Review Article

\title{
The Beneficial Role of Natural Endocrine Disruptors: Phytoestrogens in Alzheimer's Disease
}

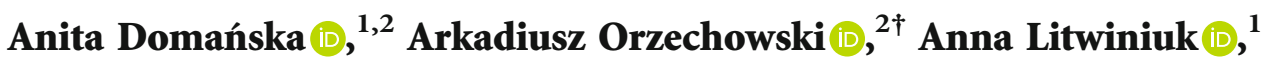 \\ Małgorzata Kalisz $\mathbb{D}^{1},{ }^{1}$ Wojciech Bik $\left(\mathbb{D},{ }^{1}\right.$ and Agnieszka Baranowska-Bik ${ }^{3}{ }^{3}$ \\ ${ }^{1}$ Department of Neuroendocrinology, Centre of Postgraduate Medical Education, Marymoncka 99/103, 01-813 Warsaw, Poland \\ ${ }^{2}$ Department of Physiological Sciences, Institute of Veterinary Medicine, Warsaw University of Life Sciences-SGGW, \\ Nowoursynowska 166, 02-787 Warsaw, Poland \\ ${ }^{3}$ Department of Endocrinology, Centre of Postgraduate Medical Education, Cegłowska 80, 01-809 Warsaw, Poland \\ ${ }^{\dagger}$ Deceased \\ Correspondence should be addressed to Anita Domańska; an_ita@wp.pl
}

Received 17 June 2021; Accepted 17 August 2021; Published 6 September 2021

Academic Editor: Antonella Smeriglio

Copyright (c) 2021 Anita Domańska et al. This is an open access article distributed under the Creative Commons Attribution License, which permits unrestricted use, distribution, and reproduction in any medium, provided the original work is properly cited.

\begin{abstract}
Alzheimer's disease $(\mathrm{AD})$ is the most common form of dementia with a growing incidence rate primarily among the elderly. It is a neurodegenerative, progressive disorder leading to significant cognitive loss. Despite numerous pieces of research, no cure for halting the disease has been discovered yet. Phytoestrogens are nonestradiol compounds classified as one of the endocrinedisrupting chemicals (EDCs), meaning that they can potentially disrupt hormonal balance and result in developmental and reproductive abnormalities. Importantly, phytoestrogens are structurally, chemically, and functionally akin to estrogens, which undoubtedly has the potential to be detrimental to the organism. What is intriguing, although classified as EDCs, phytoestrogens seem to have a beneficial influence on Alzheimer's disease symptoms and neuropathologies. They have been observed to act as antioxidants, improve visual-spatial memory, lower amyloid-beta production, and increase the growth, survival, and plasticity of brain cells. This review article is aimed at contributing to the collective understanding of the role of phytoestrogens in the prevention and treatment of Alzheimer's disease. Importantly, it underlines the fact that despite being EDCs, phytoestrogens and their use can be beneficial in the prevention of Alzheimer's disease.
\end{abstract}

\section{Alzheimer's Disease}

1.1. Introduction. Nowadays, dementia is estimated to affect over 45 million people worldwide and is believed to reach up to 115 million by 2050 [1]. Alzheimer's disease (AD) is a complex, neurodegenerative disorder of the central nervous system (CNS), which accounts for up to $70 \%$ of dementias [2]. Dementia can also be caused by other factors, such as brain injuries, vascular disorders, and numerous other diseases, e.g., Parkinson's disease (PD), Huntington's disease (HD), or Creutzfeldt-Jakob disease (CJD).

Alzheimer's disease was first identified more than a century ago by Alois Alzheimer, a German psychiatrist. In 1906, he described a case of dementia observed in a 50-year-old woman. He continued to track the progress of her disease until 1906 when she died [3]. He found at autopsy of her brain characteristic pathological microscopic changes, known today as visible gliosis around numerous senile plaques (SP) and abundant neurofibrillary tangles (NFT) [4]. Currently, about 35 million patients in the world are suffering from Alzheimer's disease.

The etiology and pathogenesis of Alzheimer's disease are complex and despite the efforts of researchers, the mechanisms are still not transparent. Much is yet to be discovered when it comes to precise biological processes. The major challenges include reasons why the disease progresses faster in some patients and slower in others, and finally, how to prevent, stop, or at least slow down the progression of $\mathrm{AD}$ [5]. The majority of $\mathrm{AD}$ patients ( $>95 \%)$ have sporadic onset, and less than $5 \%$ of the cases are related to dominant 
gene mutations, including APP, PS1, or PS2 genes [3]. Notably, $\mathrm{AD}$ is a disease that begins much earlier before its symptoms arise, and according to Alzheimer's Association [5], it can be even up to 20 years earlier. Thus, early detection seems to be crucial for intervention in coping with the disease.

1.2. Symptoms and Stages of Alzheimer's Disease. Alzheimer's disease causes both cognitive and noncognitive symptoms and signs. Importantly, the symptoms and progress of $\mathrm{AD}$ vary among individuals. This heterogeneity is particularly challenging to patients, their families, and clinicians, considering the difficulty in forecast and recognition functional impairment and other upcoming symptoms [6]. Importantly, AD is characterized by neuronal degeneration in selective brain regions involved in cognition (hippocampus, entorhinal, and frontal cortices) and emotional behaviors (amygdala, prefrontal cortex, and hypothalamus). Current research identifies three stages of $\mathrm{AD}$ : preclinical Alzheimer's disease, mild cognitive impairment (MCI) due to Alzheimer's disease, and dementia due to Alzheimer's disease. Symptoms and signs of the disease are present in the last two stages, but importantly with a varying degree [7].

Preclinical AD is a stage in which patients have measurable and significant structural changes in the brain, composition of cerebrospinal fluid (CSF), and presence of blood biomarkers. On the other hand, symptoms such as memory loss are not developed at this point. Importantly, not all individuals with raised Alzheimer's biomarkers progress to develop dementia or mild cognitive decline, but most of them do [8]. Because of no perceptible symptoms, this stage of the disease is notably hard to detect.

MCI due to $\mathrm{AD}$ is a stage in which biomarkers such as elevated levels of beta-amyloid protein or neurofilament light chain (NFL) in CSF are raised. Moreover, an individual in this stage of the disease shows cognitive decline much greater than the one expected for her/his age. Importantly, the decline does not always impede patients' everyday activities.

Dementia due to $\mathrm{AD}$ is a stage in which prominent thinking, memory, and behavioral impairment affect an individual's daily life. Additionally, evidence of AD-related brain changes is also observed. Patients suffering from the mild stage of Alzheimer's dementia are frequently able to function autonomously in many areas, such as participating in their favorite activities, driving, and working. However, they should be assisted with some tasks to maximize their safety. In the next stage, the moderate stage of Alzheimer's dementia, individuals may find it hard to communicate and conduct their daily tasks, such as taking a shower, dressing up, or brushing their teeth. In this stage, visible changes in their behavior and personality are observed. For instance, they may get irritated easily, become anxious, fearful, or overly suspicious. The last stage of $\mathrm{AD}$ is the severe stage of Alzheimer's dementia. Patients suffering from this stage of the disease need help in every area of their lives and are likely to require around-the-clock care. Unambiguous AD diagnosis is classically made postmortem, once neuropathology has confirmed the specific senile plaque and fibrillary tangle deposition in an individual with clinical diagnostic symptoms observed during life.

1.3. Hypotheses of the Onset. There are numerous hypotheses when and how it comes to the induction and the beginning of $\mathrm{AD}$. The ones which are considered to be crucial are the inflammation hypothesis, cholinergic hypothesis, tau hypothesis, amyloid $\beta(\mathrm{A} \beta)$ cascade hypothesis, and oxidative stress hypothesis.

1.3.1. Inflammation Hypothesis. The inflammation hypothesis suggests that reactive gliosis with coexisting neuroinflammation should be considered crucial in AD pathology. The theory assumes that reactive microglia and astrocytes which surround amyloid plaques secrete numerous proinflammatory cytokines. Thus, they are regarded as an early, prime mover in $\mathrm{AD}$ advancement [9].

1.3.2. Cholinergic Hypothesis. In turn, the cholinergic hypothesis is drawn from observations of noticeable cholinergic neuronal cell loss in $\mathrm{AD}$ postmortem brains [10]. Besides, neuroscientists confirm the significance of cholinergic neurotransmission in cognitive function, especially in attention and memory encoding [11]. Thus, this hypothesis procured the successful approval of cholinesterase inhibitors in clinical practice [12].

1.3.3. Tau Hypothesis. The tau hypothesis is related to a microtubule-associated protein, tau, which works as a reinforcement for a cytoskeleton in an axon. Under pathological conditions, such as Alzheimer's disease, tau proteins tend to aggregate forming intracellular NFT, thus weakening the cytoskeleton. As a result, not only the structure of the cell is deformed but also the intracellular transport of neurotransmitters encapsulated in vesicles is severely impaired. The aforementioned processes inevitably lead to neurodegeneration [13].

1.3.4. Amyloid $\beta$ Hypothesis. Another important hypothesis concerns the $\mathrm{A} \beta$ protein as the main trigger of $\mathrm{AD}$ development. Amyloid-beta is produced by endoproteolysis of amyloid precursor protein (APP), encoded by the APP gene. Depending on enzymes that take part in the process, the processing of APP can be divided into two pathways, the nonamyloidogenic pathway and the amyloidogenic pathway [14]. The first pathway, also called the $\alpha$ pathway, is conducted by two main enzymes $\alpha$-secretase and $\gamma$-secretase. As a result, soluble APP (sAPP) is produced, which is not harmful to the organism. The second pathway is called the $\beta$ pathway. In this process, APP is hydrolyzed by $\beta$-secretase (BACE1) and then by $\gamma$-secretase, and in consequence, insoluble and toxic $\mathrm{A} \beta$ is created. Under normal conditions, $\mathrm{A} \beta$ protein is formatted in a very small quantity, since APP cleavage is mainly based on the $\alpha$ pathway. Importantly, a limited amount of APP is processed via the second pathway but the $\mathrm{A} \beta$ form is efficiently eliminated by the immune system. In unusual conditions, i.e., some mutations of $A P P$ gene, such as the Lys670Asn/Met671Leu (Swedish mutation), APP is prone to be processed by the $\beta$ pathway, resulting in an excessive accumulation of insoluble $\mathrm{A} \beta$ and 
eventually the development of senile plaques [15]. Importantly, $A \beta$ has been the primary target for diseasemodifying AD therapies for decades, but so far, $\mathrm{A} \beta$-focused approaches have produced disappointing results in clinical experiments.

1.3.5. Oxidative Stress Hypothesis. Undoubtedly, oxidative stress plays an important role in the pathogenesis of $\mathrm{AD}$. The brain exploits more oxygen than any other organ, and mitochondrial respiration is essential for neurons. Nevertheless, the high demand for oxygen increases the threat of reactive oxygen species (ROS) generation. Numerous researches support the concept that oxidative stress and nitrosative stress have a causative role in the pathogenesis of AD leading to the damage of fundamental cellular elements such as nucleic acids, lipids, and proteins [16]. Additionally, elevated levels of $\mathrm{A} \beta$ have been reported to be associated with increased concentrations of oxidation products formed from the aforementioned substances. By contrast, brain regions with low $A \beta$ levels (e.g., cerebellum) did not show any increase in oxidative stress markers [17]. Oxidative stress (OS) refers to a circumstance in which ROS production overwhelms the cellular antioxidant defense systems that consist of antioxidant enzymes, such as superoxide dismutase (SOD), glutathione peroxidase (GPx), catalase, glutaredoxins, and thioredoxins, and also of nonenzymatic antioxidant factors [18]. Importantly, reduction or loss of function of the antioxidant enzymes, as denoted by decreased specific activity, has been reported in AD [19].

1.3.6. Mitochondria Hypothesis. When discussing the impact of $\mathrm{OS}$ on $\mathrm{AD}$, it is worth mentioning the role of mitochondria and their dysfunction, through the production of ROS, as an important factor involved in the pathogenesis of $\mathrm{AD}$. Growing evidence, such as documentation of disease staging generated by Alzheimer's Disease Neuroimaging Initiative, supports the notion that $\mathrm{AD}$ is not a linear downstream consequence of $\mathrm{A} \beta$ or SP deposition alone, but rather should be considered as a multifactorial disease [20, 21]. Some researchers insist that mitochondrial dysfunction is a dominant insult driving the most common, sporadic late-onset $\mathrm{AD}$ pathophysiology and refer to this pathology as a "mitochondrial cascade hypothesis" [22].

\section{Alzheimer's-Like Diseases}

Numerous important observations regarding AD and other related dementias have been made in animal studies. Although none of the existing models entirely exhibits the complete spectrum of this insidious human disease, critical aspects of $\mathrm{AD}$ pathology and disease process can be effortlessly outlined. Such diseases in animals are oftentimes called Alzheimer's-like diseases (ALD). Interestingly, there is only one group of animals, dogs, which has their own ALD named, and it is called canine cognitive dysfunction (CCD). What is worth highlighting, the vast majority of the transgenic animal models of ALD represent the familial form of Alzheimer's disease. Moreover, there are only a few studies regarding the sporadic form of AD in living ani- mals other than companion animals. The reason for this is surprisingly simple as wild animals suffering from ALD are not able to be studied as neatly as domestic animals are.

Interestingly, many domestic animals exhibit several behavioral changes in their elderly years, e.g., they tend to display spatial disorientation, change relationships with their owners, change their day-night pattern, lose cognition, or simply exhibit inappropriate vocalization [14]. Importantly, except for behavioral symptoms, there are also numerous neuropathological manifestations found in animals that are similar or the same as in $\mathrm{AD}$ including $\mathrm{A} \beta$ oligomers, senile plaques, neuronal degradation and loss, $\mathrm{AD}$ biomarkers found in CSF, vascular amyloid, dysfunction in neurotransmitter systems, decreased neurogenesis, increased oxidative stress, and oxidative damage [23-27].

\section{Endocrine Disruptors}

Notably, scientists presume that AD is mostly caused by a combination of genetic, lifestyle, and environmental factors that affect the brain over time. Many studies point to environmental chemicals as an important component of neurological diseases' onset [28] Synthetic chemicals have become an inseparable part of people's lives, and some of these chemicals have been identified as endocrine disruptor chemicals (EDCs) or endocrine disruptors (EDs).

Endocrine disruptors are exogenous substances, mixtures of chemicals, or nonchemical exogenous factors that interfere with the human endocrine system, leading to adverse effects on hormonally controlled functions [29,30]. Even though it is facile to automatically assume that EDCs are synthetic substances only, in fact, they are heterogeneous and vary from synthetic to natural chemicals. The best-known synthetic EDCs are polychlorinated biphenyls (PCB), plasticizers, pesticides, fungicides, and pharmaceutical agents. The most popular natural EDCs are phytoestrogens, predominantly found in food and drinks. There are also additional examples of natural EDCs, such as nicotine or, surprisingly, light [31]. Importantly, all of the aforementioned chemicals are widespread in the environment. EDCs interfere with hormone activities by mimicking hormones, promoting responses at improper times, or by halting hormone action, thus leading to alterations in the hormonal and homeostatic systems, and interfering with the ability of the body for communicating and responding to the environmental stimuli. EDCs tend to have a low binding affinity for hormone receptors, and their ability to activate or block hormone receptors may vary. Although it is generally difficult to define a negative effect, some researchers consider any biological response to an endocrine disruptor to be an adverse event [32].

Endocrine disruptors can be found in food, consumer products, water, soil, wildlife, and in people who were exposed to EDs through ingestion, inhalation, dermal contact, or injection. Endocrine disruptors can be divided into two large groups: chemicals and nonchemical exogenous factors. Subsequently, chemical EDs can be categorized into three primary groups: pesticides (e.g., glyphosate, dichlorodiphenyltrichloroethane (DDT)), chemicals in consumer products (e.g., parabens and heavy metals), and food contact 
materials (e.g., bisphenol A (BPA) and phthalates) [33]. When it comes to nonchemical EDCs, a good example could be light [34].

Detrimental properties of EDs are well known to scientists, and importantly, there is a growing awareness regarding them in society. These substances are called disruptors not without a reason: exposure to EDs leads to increased incidence and prevalence of cancer; they are associated with the development of learning disabilities, deformations, impairing sexual development; and they can be highly teratogenic $[35,36]$. Notably, endocrine disruptors have been linked to numerous diseases, e.g., attention-deficit hyperactivity disorder (ADHD), PD, diabetes mellitus, cardiovascular diseases, obesity, early puberty, infertility and other reproductive disorders, children and adult cancers, and $\mathrm{AD}$ [37]. Curiously, EDCs may lead to alterations in microbiota residing in the gut, which in turn may lead to neurobehavioral disorders like autism spectrum disorders [38].

A critical group of endocrine disruptors seems to be the dietary endocrine disruptors. Undeniably, food is essential for human life, and it plays a crucial role in determining the health and well-being of the consumer. Since food is the source of energy for humans, it is also one of the most significant sources of endocrine disruptors in our organisms. Importantly, dietary endocrine disruptors are not originated from food exclusively. Surely, there are numerous EDCs of animal or plant sources just like phytoestrogens, but it is worth mentioning that endocrine disruptors found in food are also pesticides (e.g., endosulfan or carbaryl), metals (e.g., aluminum or antimony), or plasticizers (e.g., bisphenol A or phthalates). When the term endocrine disruptors was used for the first time, scientists used it mainly to discuss the adverse effect of a certain substance on the endocrine system. Oral intake of EDCs was described to result in reduced fertility in men and women; breast, endometrial, and testicular cancer; birth defects of reproductive organs; and changes in the onset of puberty [39]. Nowadays, scientists are aware that the intake of dietary EDCs may lead to numerous diverse side effects. Polychlorinated biphenyls, for example, due to their lipophilic nature, remain global contaminants in the human body. They are proven to have neurotoxic, carcinogenic, immunotoxic, hepatotoxic, nephrotoxic, and cytotoxic effects in numerous experimental models and human studies [40]. Pesticides like carbaryl or endosulfan, in turn, have confirmed influence on developing obesity and metabolic disorders, deteriorating thyroid homeostasis and hypothalamo-pituitary axis, and causing hormone-sensitive cancers [41]. Plasticizers, which eagerly migrate from plastic packaging to food, are known to have serious neurotoxic effects, especially in children and pregnant women [42]. Similarly, the harmful impact has been denoted in the case of metals, which have a potential diabetogenic role and are denoted as EDCs inducing severe testicular damage [43].

Despite their bad fame, endocrine disruptors are increasingly described to have numerous positive side effects, and importantly, many of them are already confirmed by studies. Since AD is still a bit of a riddle for scientists, we decided to shed new light on some well-known EDs and EDCs and their presumed or confirmed roles in AD.

\section{Phytoestrogens}

Phytoestrogens are nonsteroidal, plant-derived compounds that may mimic or interact with estrogen hormones in mammals. They exhibit natural structural similarity to $17 \beta$-estradiol (E2), which is the most abundant circulating estrogen and the primary female sex hormone at the same time. Thus, phytoestrogens can easily interplay with estrogen receptors (ERs) and mediate estrogenic responses. Curiously, among two currently known forms of estrogen receptors (ER $\alpha$ and $\mathrm{ER} \beta$ ), phytoestrogens have a slightly higher relative binding affinity for $\operatorname{ER} \beta$ [44]. Importantly, estrogen receptors' subtype distribution varies across tissues and cell types. Moreover, it changes over the lifespan and is sexually dimorphic [45]. When bound to estrogen receptors, phytoestrogens can commence either transcription or rapid, nongenomic actions via numerous mechanisms and pathways.

Transcription induced by phytoestrogens can be initiated through interactions with the estrogen response element or by binding early immediate genes, such as Jun and Fos [46]. When it comes to the nongenomic actions of phytoestrogens, it is believed that this kind of activity develops at the extracellular surface of the cell membrane, which means that a potential endocrine disruptor does not have to enter the cell in order to be active. The binding of phytoestrogens to ERs activates second messenger pathways, leading to such cellular responses as the rise of intracellular cAMP (cyclic adenosine monophosphate) or calcium levels, or promotion of nitric oxide release contributing to the stimulation of signal transduction pathways crucial, e.g., neuronal signaling or neuronal differentiation [47]. Importantly, a growing number of papers point out that phytoestrogens have an epigenetic activity being able to modify the action of DNA and histone methyltransferases, NAD-dependent histone deacetylases, and other modifiers of chromatin structure [48, 49]. Another molecular mechanism of phytoestrogen's activity is its ability to interfere with certain enzymes required for steroid biosynthesis and/or their degradation. For example, phytoestrogens can inhibit $11 \beta$-hydroxysteroid dehydrogenase type 1 , an enzyme that takes a part in the synthesis of bioactive glucocorticoids from their inactive precursors [50]. Notably, phytoestrogens are also able to affect sex hormone-binding globulin synthesis in the liver and thus affecting sex hormones bioavailability. For example, soya containing a large amount of phytoestrogens is known to lower the risk of some cancers due to heightening sex hormone-binding globulin levels [50, 51].

Phytoestrogens can be divided into six main classes: flavonoids, pterocarpans, enterolignans, coumestans, mycotoxins, and stilbenes, depending on their chemical structure [52]. Importantly, flavonoids have numerous subclasses, e.g., flavones, flavanones, flavonols, isoflavones, and isoflavanes. The main phytoestrogens derived from the diet are genistein, daidzein, and glycitein, which belong to isoflavones [53]. You can find a graphical classification of phytoestrogens with a focus on phytoestrogens described in the article in Figure 1. 


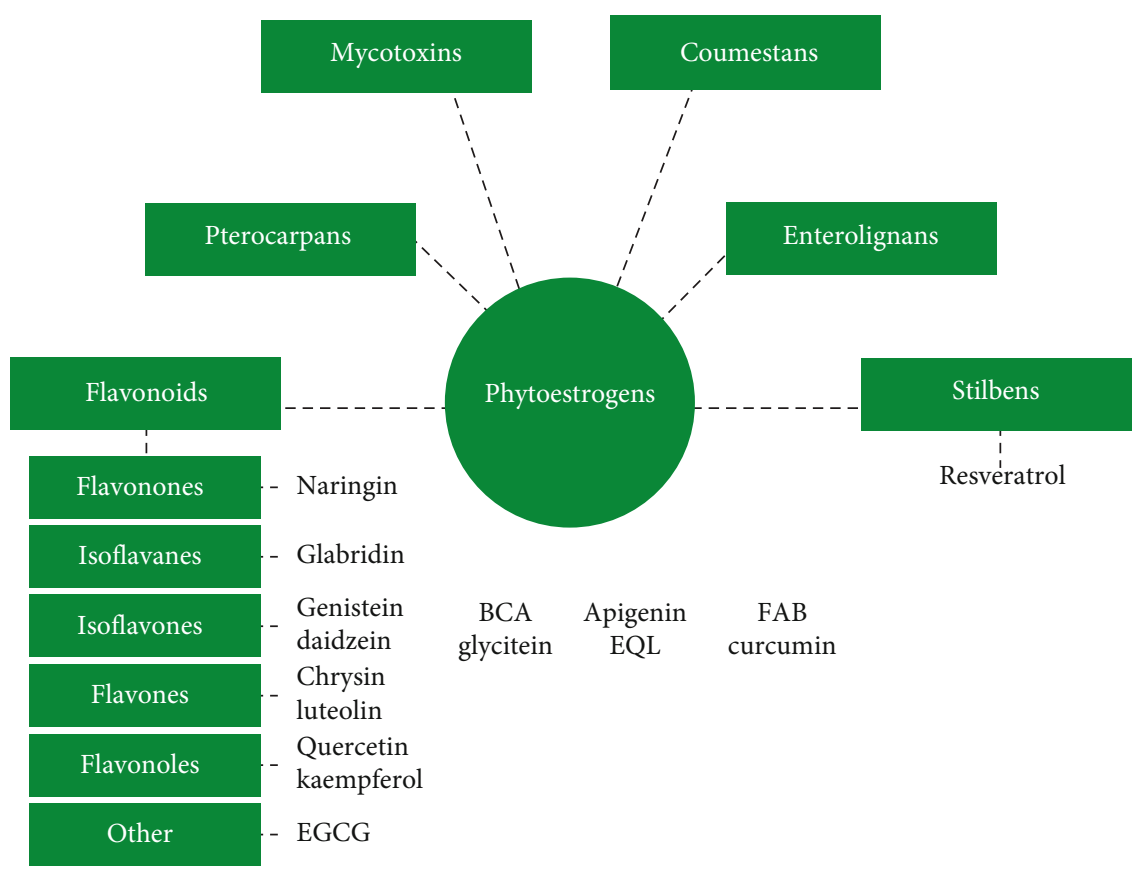

FIGURE 1: Classification of phytoestrogens with a focus on phytoestrogens described in the article.

Soy seems to be the richest source of plant estrogens. Interestingly, studies have shown great variability in isoflavone content and composition in soybeans, depending not only on the variety of soy but also on the environmental conditions [54]. Importantly, soybean is prevalently used in the food industry, including milk and meat substitutes, and has become increasingly widespread over the past 20 years. Even the pet-food industry uses heaps of soybeans and soybean-related products in their search. Back in 1998, Setchell suggested that the fertility problems of captive cheetahs could be related to the presence of soy isoflavone phytoestrogens in the standard animal diet [55].

Numerous studies indicate that phytoestrogens can exert adverse effects, especially on reproduction and fertility. Meena et al. performed a study in which pregnant rats received intraperitoneal injections of genistein at a dose level of 2,20 , or $100 \mathrm{mg} / \mathrm{kg}$ body weight for 7 days. The results indicated that male rats exposed to phytoestrogens in their mothers' wombs have impaired fertility and altered both spermatogenesis and steroidogenesis [56]. Consistent observations were made in humans in a population-based casecontrol study by Russo et al., who showed that high consumption of phytoestrogens was associated with a higher occurrence of prostate cancer [57]. Interestingly, even the widely known beneficial effects of soy intake for women with breast cancer are controversial, as in vitro studies showed that some phytoestrogens, namely, genistein and daidzein, even in the low concentrations were able to stimulate the proliferation of MCF-7 human estrogen-receptor alpha positive $(\mathrm{ER} \alpha+)$ breast cancer cells. [58].

4.1. Cognitive Function. Importantly, phytoestrogens can also have an impact on the nervous system and behavior. Interestingly, in contrast to the aforementioned systems and organs, the vast majority of the effects of phytoestrogens exerted on cognitive functioning turns out to be advantageous.

4.1.1. Cognitive Function: Human Studies. A meta-analysis of 10 placebo-controlled suitable randomized controlled trials conducted by Cheng et al. in 2015 revealed that supplementation with soy isoflavones indeed improves cognitive function and visual memory in postmenopausal women [59]. What is worth mentioning, researchers underline the importance of geographic features and treatment duration as important factors influencing the effect. A prominent study named SOPHIA was conducted on postmenopausal women [60]. Isoflavones were supplemented to women (110 mg/day), and after 12 weeks of daily supplementation, their cognitive function was assessed. It turned out that the treatment significantly improved performance in the recall of pictures and sustained attention and planning tasks [61].

Sekikawa et al., who proved that equol, a derivative of daidzein, is antiatherogenic and can improve arterial stiffness, stated that equol may help to prevent cognitive impairment or/and dementia [62].

Interestingly, very few studies included males and assessed their reaction to phytoestrogens supplementation. However, these studies provided truly captivating results. A case-control study by File et al. [63] indicated that dietary isoflavone supplementation improved cognitive function in men. Individuals received $100 \mathrm{mg}$ of isoflavones per day for 10 weeks. The isoflavones varied depending on the meal served. Importantly, the diet contained a wide range of soya-containing foods, such as soya milk drinks or puddings, soya flour, or simply soya beans. Young, healthy adults exhibited a significant improvement in both short-term and long-term memory, and additionally, the mental 
flexibility of studied subjects was improved. Li et al. [64], in turn, pointed out that a diet rich with phytoestrogens affected boys' brains more likely than girls'. In their study, they examined infants fed exclusively with soy formula from the first weeks of their life throughout the first year of life. The study also suggested that a soy-based diet may influence later life brain anatomy and function; however, the changes were modest, and therefore, the results cannot lead to any clinically relevant deficits or abnormal outcomes. Additionally, Thorp et al. [65] showed that oral isoflavone supplementation (capsules with $116 \mathrm{mg}$ of isoflavone equivalents daily: $68 \mathrm{mg}$ of daidzein, $12 \mathrm{mg}$ of genistein, $36 \mathrm{mg}$ of glycitin for six weeks) significantly enhanced spatial memory in men.

4.1.2. Cognitive Function: Animal Studies. Unquestionably, the vast majority of studies regarding the impact of phytoestrogens on the cognitive system have been conducted on animals.

In 2020, Li et al. indicated that genistein has plenty of beneficial effects in diabetes mellitus-induced brain damage [66]. The authors revealed that this phytoestrogen not only improves brain insulin signaling but also increases neurotrophic support and alleviates AD-related pathologies, such as $\mathrm{A} \beta$ deposition and the level of hyperphosphorylated tau protein. As a result, cell growth and survival, synaptic plasticity, and cognitive function of such animals are significantly improved. Consistent results were reported by Park et al. [67]. They showed that genistein exerts a protective effect against neurodegeneration in mice [68].

Interestingly, as genistein has intrinsically low oral bioavailability, not only oral delivery of phytoestrogens has been investigated. Rassu et al. suggested that intranasal supplementation of genistein as nanoparticles may be considered to act as a potential preventive system against neurodegenerative disorders [69].

Due to the fact that phytoestrogens are widespread and commonly found in food and drinks, scientists have carried out studies regarding specific fares, dishes, and recipes. A study conducted on mice indicated that a Korean traditional fermented soybean paste named Doenjang alleviates neuroinflammation and neurodegeneration [70]. Another research showed that a diet containing high amounts of phytoestrogens not only reduces aggression in mice but also has a strong negative impact on the sociability of the animals [71].

Phytoestrogens, acting as estrogen agonists, can positively affect the synthesis of brain-derived neurotrophic factor (BDNF) and nerve growth factor (NGF). This hypothesis was confirmed back in 1999 by Pan et al., who showed the mRNA levels of BDNF in the frontal cortex were significantly higher in rats receiving soy isoflavones compared to those fed without any phytoestrogens [72]. NGF, in turn, increases the mRNA of choline acetyltransferase and increases its activities, thus promoting the release of acetylcholine. Importantly, NGF has an outcome principally on cholinergic neurons, which are the most prone to neurodegeneration in $\mathrm{AD}$. Moreover, certain studies pointed out that $\mathrm{NGF}$ can be crucial in slowing the progression of AD since it impedes cholinergic basal forebrain atrophy. As a result, phytoestrogens, due to their ability to promote NGF and NGF receptor expression, are more and more often believed to be potential preventative treatment against $\mathrm{AD}$ [73].

\subsection{Nervous System}

4.2.1. In Vitro Neuroprotection. Numerous studies have already indicated that phytoestrogens have neuroprotective effects against varied kinds of damage. This fact has been proven using a wide range of in vitro models.

Phytoestrogen isoflavones, principally biochanin A (BCA), significantly increase the expression of glutamate oxaloacetate transaminase (GOT), an enzyme that can metabolize neurotoxic glutamate, in mouse hippocampal HT4 neural cells [74]. A consistent result was confirmed by Tan et al., who indicated that BCA had strong neuroprotective effects against $\beta$-amyloid-induced neurotoxicity in PC12 cells [75]. This effect is exerted via a mitochondriadependent intrinsic apoptotic pathway. Another widely known isoflavone, apigenin, was found to give an antiapoptotic effect in murine HT22 hippocampal neuronal cells as well as in human SH-SY5Y neuroblastoma cells [76, 77]. Additionally, apigenin can reduce glutamate-induced $\mathrm{Ca}^{2+}$ signaling in cultured murine cortical neurons [78]. Combined results indicate that this isoflavone possesses strong neuroprotective properties.

Equol (EQL), a metabolite of dietary daidzein (DAI), may mitigate the activation of $\mathrm{BV}-2$ microglia. It also enhanced the neuroprotection of C6 astrocytes and N2a (Neuro2a) neuroblastoma cells [79]. One of the most recent studies regarding in vitro effects of EQL showed that this metabolite also had a neuroprotective effect against neurotoxins-induced toxicity in SH-SY5Y human neuroblastoma cells [80].

Quercetin is a well-known plant-derived antioxidant. It is one of the predominant flavonoids found in our daily diet. It has been revealed that quercetin decreased the maturation of APP, which in turn alters $\mathrm{A} \beta$ secretion and aggregation [81]. Additionally, quercetin glycosides have confirmed neuroprotective effects in such diseases as AD and PD. Magalingam et al. conducted an experiment, in which PC-12 cells pretreated with isoquercitrin and rutin were later exposed to 6-hydroxydopamine (6-OHDA), a synthetic, neurotoxic compound [82]. Cells exposed to glycosides markedly attenuated the expression of proapoptotic genes, such as Casp1, Casp3, and Casp7, when compared to the control cells.

Consistent research was carried out by Kim et al., in which quercetin and kaempferol demonstrated their neuroprotective effects by downregulating the expression of proapoptotic proteins in human SH-SY5Y cells [83]. Additionally, the aforementioned phytoestrogens significantly increased the viability of cells treated with $\mathrm{A} \beta$.

Importantly, phytoestrogens showed a beneficial impact on cells not only in cellular models of AD. Abbruzzese et al. experimented with a startling outcome: genistein and BCA played dual roles in the regulation of autophagy [84]. Depending on whether autophagy is a neuroprotective and prosurvival mechanism or prodeath mechanism, they acted 
either as autophagy initiation enhancers or as autophagy initiation inhibitors. The experiment was conducted on cortical neurons of Wistar rats in the model of ischemia that is a crucial process in many neurodegenerative diseases.

Flavonoid agathisflavone (FAB) is a phytoestrogen derived from the plant Poincianella pyramidalis. FAB significantly ameliorated neuroinflammation induced by LPS (lipopolysaccharide) and proinflammatory cytokines in cocultures of glia and neurons. This finding undoubtedly indicates that FAB has not only neuroprotective but also anti-inflammatory effects in vitro, which, in turn, may be considered as an ancillary for the treatment against numerous neurodegenerative diseases [85].

4.2.2. In Vivo Neuroprotection. Neuroprotective effects of phytoestrogens have been proven multiple times in in vivo models of AD. Ipriflavone (IPRI) is a nonhormonal isoflavone used in some countries as a treatment and prevention against osteoporosis caused by menopause. In a study by Hafez et al. on a rat model, IPRI turned out to play a great role in AChE inhibition, alleviated oxidative stress, reverted memory impairment, and, importantly, significantly increased the expression of two putative $\alpha$-secretase enzymes: ADAM10 and ADAM17 [86]. Additionally, IPRI increased the expression of pERK1/22 (phosphorylated extracellular signal-regulated kinase 1,2), a serinethreonine kinase that plays a crucial role in decreasing the BACE expression in the hippocampus. What is promising, IPRI significantly reduced tau and $\mathrm{A} \beta$ pathologies.

Apigenin is a flavonoid widely spread among fruits and vegetables, such as parsley, oranges, or onions. It has antiinflammatory, antioxygenic, antitumorigenic, and antimutagenic effects on numerous cell types [76, 87]. Importantly, apigenin plays also an important role in AD. Scientists have reported that apigenin inhibited oxidative stress in APP/PS1 double transgenic mice. Additionally, apigenin ameliorated $\mathrm{AD}$-associated memory impairment in mice and reduced the spread of $\mathrm{A} \beta$ plaques [88].

Quercetin is another phytoestrogen with strong anti-AD potential studied in vivo. In a study by Sabogal-Guaqueta et al., quercetin was administrated every 48 hours for three months on aged (21-24 months old), triple-transgenic AD model mice (3xTg-AD). Quercetin decreased not only extracellular $\beta$-amyloidosis but also microgliosis, astrogliosis, and tauopathy in the hippocampus and amygdala. Additionally, a visible reduction in $\beta$-amyloid 1-40 and $\beta$-amyloid 1-42 levels was observed. However, not only histological changes were observed but also quercetin had an enhancing effect on learning spatial memory tasks and improved risk-assessment behavior [89]. A similar conclusion was carried out by Shveta et al., who also confirmed the neuroprotective role of quercetin, but this time, the experiments were conducted on rats [90].

Numerous papers indicated that less-known phytoestrogens have also neuroprotective effects; however, these substances are still not studied sufficiently. A good example of this group could be naringin, a flavonoid found in citrus fruits, which weakens oxidative stress and neuroinflammation in vivo [91]. Some other phytoestrogens which have confirmed neuroprotective impact in vivo and are not as widely known as aforementioned compounds are luteolin (LUT), commonly found in spices like parsley or thyme [92]; chrysin (CHR), a flavonoid that interacts with TTR protein (transthyretin) and thus TTR can play its role and take a part in $\mathrm{A} \beta$ clearance $[93 ; 94]$; epigallocatechin gallate (EGCG), which is the major polyphenol component of green tea, has confirmed neuroprotective effect in vivo not only in $\mathrm{AD}$ but also in amyotrophic lateral sclerosis (ALS), multiple sclerosis (MS), and PD. EGCG, just like CHR, can bind to TTR and at the same time suppress $\beta$-amyloid fibril formation [93]. Neuroprotective effects in vivo were also observed with $\gamma$-mangostin $(\gamma$-M), originally isolated from Garcinia mangostana tree [94] and glabridin (GLA) isolated from the roots of Glycyrrhiza glabra L. [95-97].

Naturally, phytoestrogens have neuroprotective effects not only in AD models but also in a plethora of other neurodegenerative diseases. A study by Ohgomori et al. [98] showed that genistein alleviated the demyelination of mature mice oligodendrocytes induced by cuprizone (CPZ), and thus, phytoestrogens are considered to have therapeutic potential for treating patients with multiple sclerosis or those suffering from mental health disorders. Khanna et al. conducted an experiment on C57BL/6 mice, which were intraperitoneally injected with biochanin A for 4 weeks and afterward subjected to ischemic stroke injury [74]. It turned out that BCA treatment in mice induced GOT expression, attenuated stroke lesion volume, and improved sensorimotor functions. Furthermore, in the rat model of PD, BCA decreased the levels of proinflammatory cytokines such as IL-6, IL- $1 \beta$, and TNF $\alpha$ and at the same time inhibited the generation of reactive oxygen species. In this study, male Sprague-Dawley rats were treated with BCA for 21 days [99]. Another study by Wang et al. [99] revealed that BCA attenuated behavioral deficits and dopamine depletion induced by the combined effect of iron and rotenone in Sprague-Dawley rats. Equol was confirmed to have neuroprotective possibilities against neurotoxicity induced by 1-methyl-4-phenylpyridinium (MPP+) using in vivo model of $\mathrm{PD}$ including Caenorhabditis elegans (C. elegans). Importantly, EQ prolonged the survival of C. elegans exposed to MPP+ from 72 to $108 \mathrm{hrs}$ [80].

4.3. Cerebral Ischemia Injury. There is a growing number of data indicating the relationship between brain ischemia and Alzheimer's disease [100]. Besides, several studies revealed epidemiological and neuropathological factors linking ischemic brain neurodegeneration with the genotype and phenotype of Alzheimer's disease. Furthermore, Alzheimer's disease is a risk factor for stroke, and conversely, stroke enhances the risk of AD. Finally, dysregulation of Alzheimer's disease-associated genes including amyloid protein precursor, $\alpha$-secretase, $\beta$-secretase, presenilin 1, presenilin 2 , and tau protein occurs in a course of postischemic neurodegeneration [100]. Oxidative stress (OS) and neuroinflammation are crucial mechanisms in the progression of cerebral ischemia injury. Importantly, they both are components in the etiology of neurodegenerative diseases. Thus, maintaining physiological blood flow, halting OS, and limiting neuroinflammation are essential in the prevention of brain injuries [101]. 
Ever since it was denoted that men have a higher incidence of stroke compared with premenopausal women [102], estrogens are claimed to possess neuroprotective properties. This finding along with the widespread use of estrogens as hormone-replacement therapy (HRT) for amending postmenopausal syndromes caused a large number of reports insisting that estrogens may have neuroprotective effects on brain stroke. However, the results of numerous in vivo and in vitro studies are ambiguous as some confirm this hypothesis, whereas others claim that estrogens can be simply detrimental for postmenopausal women because of the potential deleterious side effects of hormone replacement therapy, such as increased cancer and stroke risk [103]. Thus, a lot of expectations are held concerning phytoestrogens, which seem to be the best and the safest alternative to estrogens.

Several phytoestrogens have been shown to strengthen endogenous antioxidant defenses. Some of them activate NRF2 (nuclear factor erythroid 2-related factor 2) and its gene targets, which are regulated by ARE (antioxidant response element) DNA sequence. Activation of the NRF2/ARE pathway provokes the production of antioxidant enzymes, such as heme oxygenase-1 (HO-1) or NAD $(\mathrm{P}) \mathrm{H}$ dehydrogenase (quinone 1) (NQO1). The examples of phytoestrogens that can activate the pathway in neurons are quercetin, curcumin, resveratrol, sulforaphane, epigallocatechin gallate, piceatannol, or brazilin [104, 105]. Some of the aforementioned phytoestrogens, like quercetin or curcumin, can additionally increase the expression of protein chaperones, involving heat-shock proteins and numerous growth factors such as BDNF, IGF (insulin-like growth factor), or FGF (fibroblast growth factor) [106]. Protein chaperones bind to other proteins, protect them, and mediate the unfolded protein response in the endoplasmic reticulum which ensues in neurons during ischemic stroke. Importantly, heat-shock protein response is a well-known and very important process of defense against ischemic strokeinduced stress conditions [107]. Heat shock proteins take a part in protein folding and protection and removal of aggregated proteins, and they could inhibit apoptotic cell death cascade [108].

\section{Hormone Replacement Therapy}

Some researches indicate that the risk of $\mathrm{AD}$ incidence and the severity of the disease differ indispensably between men and women. It is estimated that women suffer from the disease even twice as often as men. Although this discrepancy could be partially explained by differences in mean length of life, other mechanisms cannot be omitted. According to recent findings, a decrease in estrogen levels in the menopause period could be connected with AD-related brain changes [109]. Additionally, premature menopause also increases the risk of $\mathrm{AD}$ onset or development [110].

A question could be raised why estrogen depletion is so harmful to cognition processes. From the physiological point of view, estrogens act through a wide network of receptors. Two types of receptors could be distinguished, estrogen receptor alpha $(\mathrm{ER}-\alpha)$ and estrogen receptor beta (ER- $\beta)$.
ER- $\alpha$ acts as a neuroprotective element against AD by maintaining intracellular signaling cascades [111]. ER- $\beta$ is a potent regulator of the innate immune response as well as is involved in the regulation of neuronal mitochondrial function [112]. Besides, reduced expression of ER- $\alpha$ has been found in hippocampal neurons of AD subjects. Furthermore, lower expression of ER- $\beta$ was related to abnormal mitochondrial function and enhanced OS markers [111] A midlife change in neurohormonal activity in females is called the menopause transition. In this particular phase of women's life, there is a decline in the production and secretion of estrogens, mainly estradiol, from the ovaries. As an effect of the decrease of estrogen concentration, several changes in the brain are observed. Among them, there is a low estrogen-related metabolic dysfunction leading to the hypometabolic state [113].

Since data suggest that perimenopause increases a patient's vulnerability to developing not only $\mathrm{AD}$ but also other neurological diseases like PD, it may be a promising way to use hormonal replacement therapy for favorable effects on female cognitive function [114]. The coherent conclusion was also conferred by the group from Mayo Clinic. According to them, women who underwent bilateral or unilateral oophorectomy before the onset of natural menopause had a lifelong increased risk of cognitive impairment and dementia $[115,116]$.

Numerous research reviews, meta-analyses, and in vivo and in vitro experiments were conducted to examine the link between estrogen replacement therapy (HRT) and its effect on $\mathrm{AD}$. In general, the results were promising. Imtiaz et al. [117] showed in their cohort study that long-term HRT was associated with a reduced risk of $\mathrm{AD}$. The consistent result was presented by Song et al. in their meta-analysis [114]. These authors confirmed that estrogen replacement therapy decreases the risk of onset and/or development of not only AD but also PD. What is worth mentioning, recent reviews indicate that the positive outcome of HRT use in the case of $\mathrm{AD}$ may depend on such factors as the length of hormone administration, duration of treatment, and an individual's risk of developing cancer or/and stroke [118].

Of note, an interesting study was performed by Luoto et al., who assessed the impact of HRT on women's health and lifestyle. It turned out that $28 \%$ of HRT users had higher education, lived in the capital city's area, had a significantly higher healthy diet factor score, and were leaner than nonusers of HRT. Importantly, the use of HRT remained a significant determinant of body mass index, waist/hip ratio, and body fat percentage [119]. In addition, a recently published meta-analysis indicated that higher levels of education were connected with false negatives of the MMSE (the MiniMental State Examination), whereas lower levels of education were associated with false positives [120].

However, except for the optimistic results, some findings put in doubt the use of estrogens not only in the prevention of $\mathrm{AD}$ but also, if not primary, in hormone replacement therapy. Savolainen-Peltonen et al. [121] in their casecontrol study indicated that for women who initiated hormone replacement therapy before the age of 60 , the use of HRT was associated with a $17 \%$ increase in the risk of $\mathrm{AD}$. 
TABLE 1: Summary of systems and processes influenced by phytoestrogens mentioned in the publication (with responding references).

$\left.\begin{array}{lcr}\hline \text { Process/organ influenced by phytoestrogens } & \text { Specification } & \text { Reference number } \\ \hline \text { Cognitive function } & \text { Human studies } & {[59-65]} \\ \hline \text { Nervous system } & \text { Animal studies } & {[66,67,68,69,70,71,72,73]} \\ \hline \text { Cerebral ischemia injury } & \text { In vivo } & {[74,76,80,86-99,130,131]} \\ \text { Hormone replacement therapy } & - & {[74-85]}\end{array}\right]$

The percentage was even higher in women who initiated HRT after the age of 60 , and it reached up to $38 \%$. Besides, not only an enhanced risk of $\mathrm{AD}$ and $\mathrm{PD}$ was observed in elderly women treated with estrogens but also increased mortality was indicated [119]. However, it should be highlighted that there is a critical period of effective estrogen treatment following menopause. The duration of this advantageous time depends on the depletion of estradiol receptors, the switch to a ketogenic metabolism by neuronal mitochondria, and a decrease of acetylcholine accompanying estradiol deficiency [122].

Interestingly, the side effects of HRT did not affect the nervous system only. For years, it was almost a dogma that any cardiovascular disease was prevented in women undergoing HRT. However, the Women's Health Initiative (WHI) trial of conjugated equine estrogens (CEE) and medroxyprogesterone acetate (MPA) showed in 2002 that HRT resulted in a significantly increased incidence of stroke and venous thromboembolism [123-125]. Because of the WHI results and other side effects of HRT, a lot of effort nowadays is put into finding a less harmful, but still efficient alternative to estrogens. Thus, phytoestrogens seem to be a very promising alternative. Importantly, phytoestrogens have an exceptional ability to act as estrogen agonists without any currently known detrimental effects. They could be the perfect solution and reconcilement between the positive impact of estrogens on $\mathrm{AD}$ and their harmful effects on health. The enthusiasm about the use of phytoestrogens emerged from epidemiologic studies indicating that PEs lower the risk of breast cancer and osteoporosis and mitigate the symptoms of menopause in women from countries with high phytoestrogens consumption [128, 129]. Additionally, some of the phytoestrogens own antioxidant properties in vitro through hydrogen/electron donation via hydroxyl groups; hence, they act as free radical scavengers and can suppress the progression of coronary heart disease and some types of cancer [126]. PEs are also able to upregulate the expression of manganese superoxide dismutase (MnSOD) and catalase, which enhances their antioxidant effect [125, 127]. In Table 1, you can find the summary of processes and organs affected by phytoestrogens and articles cited in the article regarding them.

There are two mechanisms by which phytoestrogens exert their impact: estrogen-mediated and nonestrogenmediated. The nonestrogen-mediated mechanisms are inclusive of any reaction in which phytoestrogen plays a unique role. This means that phytoestrogens do not compete with estrogens but simply do their "own job." They protect neurons against $O S$ and prevent the damage it causes [128]. The estrogen-mediated mechanisms, in turn, are inclusive of all reactions in which estrogen is a factor [73]. Substantially, in these mechanisms, phytoestrogens substitute estrogens when they are in low concentrations by simply binding to estrogen receptors. Examples of such mechanisms are reduction of tau protein phosphorylation, reduction of $\mathrm{A} \beta$, promotion of $\mathrm{Ca}^{+}$outflow, or enhancing acetylcholine release [129].

\subsection{Nonestrogen-Mediated Mechanisms}

5.1.1. Antioxidant Properties and Effects on Neurons. Certain amyloid-beta peptides are known for having toxic properties. Phytoestrogens, in turn, often act as their functional antagonists [134].

$\mathrm{A} \beta$ is among the factors that stimulate lipid peroxidation in the neuronal cell membrane, the process that leads to the production of reactive oxygen species and respiratory burst. Subsequently, membrane proteins can be impaired and the homeostasis of ion distribution could be broken. As a consequence, the neuronal membrane depolarizes resulting in $\mathrm{Ca}^{2+}$ inflow via the $N$-methyl-D-aspartate (NMDA) receptor channels. As a result of such phenomena, the damage of lipids and DNA aggravates even more, eventually leading to neuronal death.

Auspiciously, numerous researches indicate that estradiol (and in turn phytoestrogens) is a natural antioxidant for membrane lipid peroxidation, and it mitigates $\mathrm{A} \beta$ toxicity against neurons [135-138]. Importantly, phytoestrogens significantly improve cerebral blood circulation and, therefore, increase oxygen and nutrient supply to the brain cells [139].

\subsection{Estrogen-Mediated Mechanisms}

5.2.1. Decrease in A $\beta$ Production. What should be underlined once more is that not all APPs are detrimental to health. A large number of APPs is, in fact, advantageous. They are essential for synapses' formation, neuronal plasticity, or iron export. APPs may sustain cognitive functioning in patients with $\mathrm{AD}$ and ALD [73]. However, some APPs are precursors for neurotoxic $\mathrm{A} \beta$.

Estrogens are known to regulate the metabolism of APP. They can promote the release of APPs in cortical neurons via 


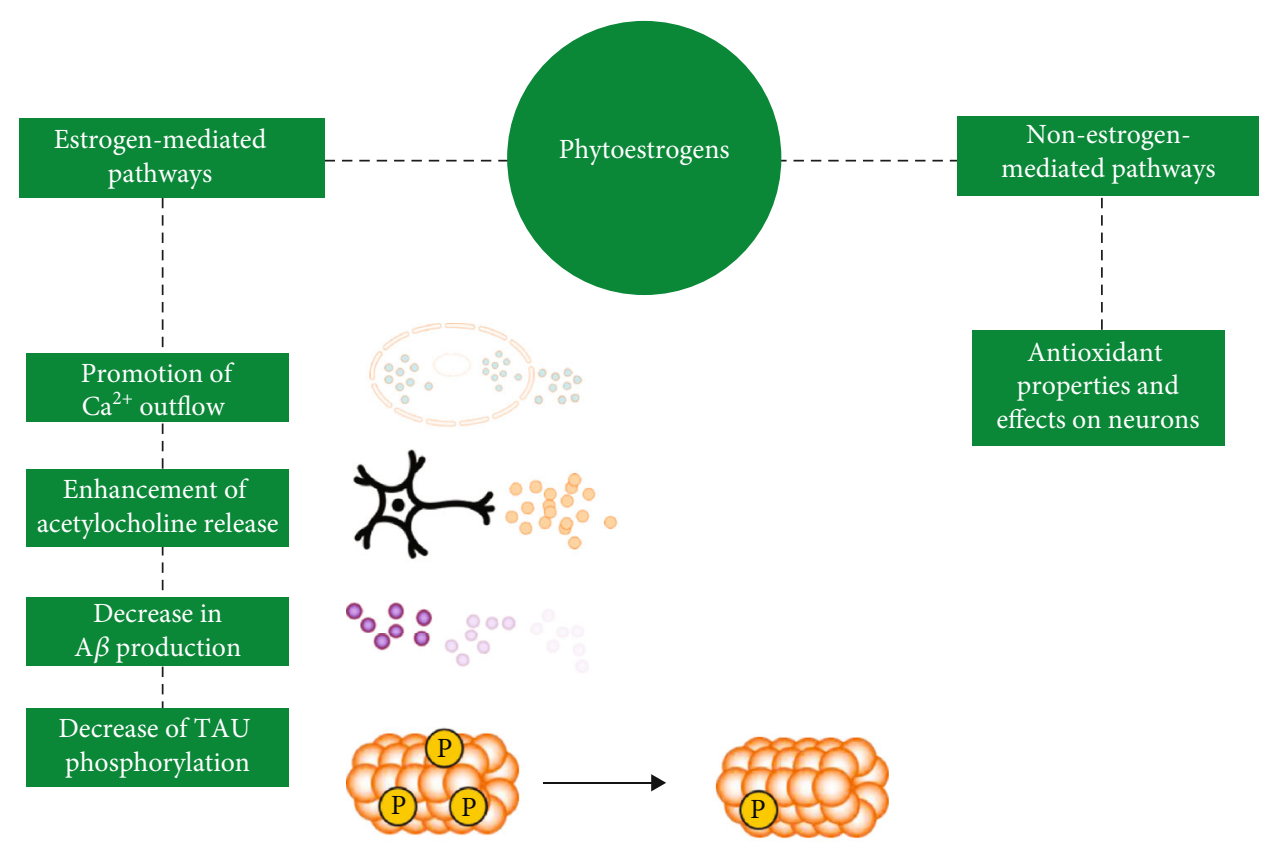

FIGURE 2: Estrogen- and nonestrogen-mediated mechanisms exerted by phytoestrogens on neurons.

the protein kinase $\mathrm{C}$ pathway. Phytoestrogens, in turn, may act as an alternative if the concentration of estrogens is not high enough, resulting in the same outcome. Regarding their ability to stimulate the excessive formation of APP in elderly individuals, phytoestrogens change the ratio between APP and $\mathrm{A} \beta$ in favor of APPs. Eventually, the $\mathrm{A} \beta$ production is reduced and serves antagonistic to the progression of $\mathrm{AD}$ $[140,141]$.

5.2.2. Decrease of Tau Protein Phosphorylation. Tau phosphorylation is one of the hallmarks of AD and ALDs. Once tau protein gets phosphorylated and converts to NFT, it destabilizes the structure of cell's cytoskeleton and impairs the functioning of a neuron and eventually leads to its death.

Estrogens are known for their anti-tau-phosphorylation features. So are phytoestrogens, exerting their effects by enhancing dephosphorylation in the proline-rich region of the tau molecule $[142,143]$. It has been observed that phytoestrogens can significantly inhibit tau phosphorylation and fibrillation and the associated cytotoxicity [144]. Additionally, according to findings of numerous in vivo and in vitro studies, inhibition of tau phosphorylation prevents endoplasmic reticulum stress-mediated neurodegeneration [145-147].

5.2.3. Enhancing Acetylcholine Release. Since phytoestrogens act as estrogens' agonists, they similarly can affect processes that involve estrogens, such as promoting axon pruning, synaptic growth, or the expression of numerous factors, e.g., NGF. NGF plays an important role in the maintenance of cholinergic neuron integrity and function, both during development and adulthood. Importantly, NGF induces the expression and activity of acetylcholine esterase (AChE), a key enzyme to degrade acetylcholine in cholinergic synapses [148]. As a result, the release of acetylcholine is promoted. It is important to note that cholinergic neurons are the target neurons for deterioration in AD and ALDs.

Many pieces of research showed that NGF plays an important role in delaying or even stopping the progression of $\mathrm{AD}$ as it fights cholinergic basal forebrain atrophy [149, 150]. Thus, more and more reports nowadays suggest that NGF, NGF receptor (NGF-R), and phytoestrogens promoting expression of NGF and NGF-R should be concerned as a potential preventative agent or, hopefully, even as a promising treatment against $\mathrm{AD}[151,152]$.

5.2.4. Promotion of $\mathrm{Ca}^{2+}$ Outflow. Phytoestrogens like estrogens can inhibit the elevation of intracellular $\mathrm{Ca}^{2+}$ concentration and reverse the disequilibrium of calcium homeostasis often caused by $\mathrm{A} \beta$. They achieve these results through the release of the intracellular $\mathrm{Ca}^{2+}$ via nongenomic signaling events, which are not influenced by extracellular $\mathrm{Ca}^{2+}$ concentration $[73,153,154]$.

Appropriate calcium homeostasis is crucial among individuals suffering from AD. Curiously, it is prevalent among this group of patients since the imbalance of $\mathrm{Ca}^{2+}$ is caused by $\mathrm{A} \beta$ peptides. When the homeostasis is unbalanced, numerous adverse effects can occur: calcium channels may be activated, there may be changes in the release of neurotransmitters, the neurilemma can be altered, and eventually, the apoptotic signaling cascade can be induced $[71,155]$.

Nowadays, phytoestrogens are widely studied in terms of their calcium-equilibrating properties, and the results are truly satisfactory. A lot of attention in these terms is attracted by genistein and other flavonoids, suggesting the importance of adequate nutrition for humans and animals $[155,156]$. You can see estrogen- and nonestrogenmediated mechanisms exerted by phytoestrogens on neurons in Figure 2. 


\section{Conclusions}

$\mathrm{AD}$ is a progressive, irreversible neurodegenerative disease affecting a growing cohort of patients. Alzheimer's-like diseases (ALDs), in turn, are group of disorders, closely related to $\mathrm{AD}$, from which our friends and life companions, animals, suffer frequently [14]. Even though numerous researches, regarding the diseases, are published daily and the knowledge about $\mathrm{AD}$ and ALDs is constantly growing, there is still no discovered nor invented drug, which would reverse or ultimately inhibit the development of the disease. Moreover, the medications that are already in use provide symptomatic treatment only. Besides, many of them tend to lower their effectiveness over time [157]. Furthermore, drugs that are broadly used nowadays, like rivastigmine, donepezil, or memantine, have multiple side effects impeding the everyday life and functioning of patients. Therefore, undoubtedly, a new approach should be concerned in terms of fighting against AD and ALDs.

Although phytoestrogens are commonly known as endocrine disruptors and by definition could have a negative impact on the endocrine system, they also have an enormous potential to influence cognition and brain functioning beneficially. Numerous in vitro and in vivo studies confirm that they do have neuroprotective and antioxidant effects and indeed mitigate the progression of $\mathrm{AD}$ in humans as well as ALDs in animals. Together with their widespread availability, multifariousness, and their positive impact on other disorders and ailments, phytoestrogens appear to be a promising medicament in the proximate future. Needless to say, more research is needed to provide indisputable confirmation of phytoestrogens' role not only in $\mathrm{AD}$ and ALDs but also in other aspects of well-being.

After all, an ancient proverb says "The enemy of my enemy is my friend". Hence, perhaps we should stop considering phytoestrogens as disruptors only, and focus on "our" evident, mutual opponents, such as Alzheimer's and Alzheimer's-like diseases.

$\begin{array}{ll}\text { Abbreviations } \\ \text { 6-OHDA: } & \text { 6-hydroxydopamine } \\ \text { AChE: } & \text { Acetylcholinesterase } \\ \text { AD: } & \text { Alzheimer's disease } \\ \text { ALD: } & \text { Alzheimer's-like diseases } \\ \text { ALS: } & \text { Amyotrophic lateral sclerosis } \\ \text { APP: } & \text { Amyloid precursor protein } \\ \text { ARE: } & \text { Antioxidant response element } \\ \text { A } \beta: & \text { Amyloid } \beta \\ \text { BACE1: } & \beta \text {-Secretase } \\ \text { BCA: } & \text { Biochanin A } \\ \text { BDNF: } & \text { Brain-derived neurotrophic factor } \\ \text { BPA: } & \text { Bisphenol A } \\ \text { cAMP: } & \text { Cyclic adenosine monophosphate } \\ \text { CCD: } & \text { Canine cognitive dysfunction } \\ \text { CEE: } & \text { Conjugated equine estrogens } \\ \text { CHR: } & \text { Chrysin } \\ \text { CJD: } & \text { Creutzfeldt-Jakob disease }\end{array}$

\begin{tabular}{|c|c|}
\hline CNS: & Central nervous system \\
\hline CPZ: & Cuprizone \\
\hline CSF: & Cerebrospinal fluid \\
\hline DAI: & Daidzein \\
\hline DDT: & Dichlorodiphenyltrichloroethane \\
\hline E2: & $17 \beta$-estradiol \\
\hline ED: & Endocrine disruptor \\
\hline EDC: & Endocrine disruptor chemical \\
\hline EGCG: & Epigallocatechin gallate \\
\hline EQL: & Equol \\
\hline ER: & Estrogen receptors \\
\hline ER- $\alpha$ : & Estrogen receptor alpha \\
\hline ER- $\beta$ : & Estrogen receptor beta \\
\hline FAB: & Flavonoid agathisflavone \\
\hline FGF: & Fibroblast growth factor \\
\hline GLA: & Glabridin \\
\hline GOT: & Glutamate oxaloacetate transaminase \\
\hline GPx: & Glutathione peroxidase \\
\hline HD: & Huntington's disease \\
\hline HO-1: & Heme oxygenase-1 \\
\hline HRT: & Hormone-replacement therapy \\
\hline IGF: & Insulin-like growth factor \\
\hline IPRI: & Ipriflavone \\
\hline LPS: & Lipopolysaccharide \\
\hline LUT: & Luteolin \\
\hline MCI: & Mild cognitive impairment \\
\hline MnSOD: & Manganese superoxide dismutase \\
\hline MPA: & Medroxyprogesterone acetate \\
\hline MPP+: & 1-methyl-4-phenylpyridinium \\
\hline MS: & Multiple sclerosis \\
\hline NFL: & Neurofilament light chain \\
\hline NFT: & Neurofibrillary tangles \\
\hline NGF: & Nerve growth factor \\
\hline NGF-R: & NGF receptor \\
\hline NMDA: & N-methyl-D-aspartate \\
\hline NQO1: & NAD(P)H dehydrogenase \\
\hline NRF2: & Nuclear factor erythroid 2-related factor 2 \\
\hline OS: & Oxidative stress \\
\hline PCB: & Polychlorinated biphenyls \\
\hline PD: & Parkinson's disease \\
\hline ROS: & Reactive oxygen species \\
\hline sAPP: & Soluble amyloid precursor protein \\
\hline SOD: & Superoxide dismutase \\
\hline SP: & Senile plaques \\
\hline TPO: & Thyroid peroxidase \\
\hline TTR: & Transthyretin \\
\hline WHI: & Women's Health Initiative \\
\hline$\gamma-\mathrm{M}:$ & $\gamma$-Mangostin. \\
\hline
\end{tabular}

\section{Data Availability}

Please contact with the main author of the work by email: adomanska@cmkp.edu.pl.

\section{Conflicts of Interest}

The authors declare no conflicts of interest. 


\section{Acknowledgments}

We dedicate this review to our teacher and friend, Arkadiusz Orzechowski. His scientific curiosity, integrity, insight and humor will be sorely missed.

\section{References}

[1] M. Rochoy, V. Rivas, E. Chazard et al., "Factors associated with Alzheimer's disease: an overview of reviews," The Journal Of Prevention of Alzheimer's Disease, vol. 6, no. 2, pp. 121-134, 2019.

[2] J. Garre-Olmo, "Epidemiología de la enfermedad de Alzheimer y otras demencias," Revista de Neurología, vol. 66, no. 11, pp. 377-386, 2018.

[3] P. P. Liu, Y. Xie, X. Y. Meng, and J. S. Kang, "History and progress of hypotheses and clinical trials for Alzheimer's disease," Signal Transduction and Targeted Therapy, vol. 4, no. 1, 2019.

[4] M. Zvěřová, "Clinical aspects of Alzheimer's disease," Clinical Biochemistry, vol. 72, pp. 3-6, 2019.

[5] Alzheimer's Association, "2021 Alzheimer's disease facts and figures," Alzheimers Dement, vol. 17, no. 3, pp. 327-406, 2021.

[6] R. T. Gottesman and Y. Stern, "Behavioral and psychiatric symptoms of dementia and rate of decline in Alzheimer's disease," Frontiers in Pharmacology, vol. 10, p. 1062, 2019.

[7] G. M. McKhann, D. S. Knopman, H. Chertkow et al., “The diagnosis of dementia due to Alzheimer's disease: recommendations from the National Institute on Aging-Alzheimer's Association workgroups on diagnostic guidelines for Alzheimer's disease," Alzheimer's \& Dementia, vol. 7, no. 3, pp. 263269, 2011.

[8] D. A. Bennett, J. A. Schneider, Z. Arvanitakis et al., "Neuropathology of older persons without cognitive impairment from two community-based studies," Neurology, vol. 66, no. 12, pp. 1837-1844, 2006.

[9] X. Du, X. Wang, and M. Geng, "Alzheimer's disease hypothesis and related therapies," Translational Neurodegeneration, vol. 7, no. 1, 2018.

[10] R. S. Convery, M. R. Neason, D. M. Cash et al., "Basal forebrain atrophy in frontotemporal dementia," NeuroImage: Clinical, vol. 26, p. 102210, 2020.

[11] M. E. Hasselmo and M. Sarter, "Modes and models of forebrain cholinergic neuromodulation of cognition," Neuropsychopharmacology, vol. 36, no. 1, pp. 52-73, 2011.

[12] F. Zemek, L. Drtinova, E. Nepovimova et al., "Outcomes of Alzheimer's disease therapy with acetylcholinesterase inhibitors and memantine," Expert Opinion on Drug Safety, vol. 13, no. 6, pp. 759-774, 2014.

[13] M. R. Brier, B. Gordon, K. Friedrichsen et al., "Tau and A $\beta$ imaging, CSF measures, and cognition in Alzheimer's disease," Science Translational Medicine, vol. 8, no. 338, article 338ra66, 2016.

[14] A. Gołaszewska, W. Bik, T. Motyl, and A. Orzechowski, "Bridging the gap between Alzheimer's disease and Alzheimer's-like diseases in animals," International Journal of Molecular Sciences, vol. 20, no. 7, p. 1664, 2019.

[15] S. Liu, Y. P. Sun, X. L. Gao, and Y. Sui, "Knowledge domain and emerging trends in Alzheimer's disease: a scientometric review based on CiteSpace analysis," Neural Regeneration Research, vol. 14, no. 9, pp. 1643-1650, 2019.

[16] D. A. Butterfield, M. L. Bader Lange, and R. Sultana, "Involvements of the lipid peroxidation product, HNE, in the pathogenesis and progression of Alzheimer's disease," Biochimica et Biophysica Acta (BBA) - Molecular and Cell Biology of Lipids, vol. 1801, no. 8, pp. 924-929, 2010.

[17] C. Cheignon, M. Tomas, D. Bonnefont-Rousselot, P. Faller, C. Hureau, and F. Collin, "Oxidative stress and the amyloid beta peptide in Alzheimer's disease," Redox Biology, vol. 14, pp. 450-464, 2018.

[18] A. Tramutola, C. Lanzillotta, M. Perluigi, and D. A. Butterfield, "Oxidative stress, protein modification and Alzheimer disease," Brain Research Bulletin, vol. 133, pp. 88-96, 2017.

[19] T. S. Kim, C. U. Pae, S. J. Yoon et al., "Decreased plasma antioxidants in patients with Alzheimer's disease," International Journal of Geriatric Psychiatry, vol. 21, no. 4, pp. 344-348, 2006.

[20] D. P. Veitch, M. W. Weiner, P. S. Aisen et al., "Understanding disease progression and improving Alzheimer's disease clinical trials: recent highlights from the Alzheimer's Disease Neuroimaging Initiative," Alzheimer's \& Dementia, vol. 15, no. 1, pp. 106-152, 2019.

[21] Y. Iturria-Medina, F. M. Carbonell, R. C. Sotero, F. Chouinard-Decorte, and A. C. Evans, "Alzheimer's Disease Neuroimaging Initiative. Multifactorial causal model of brain (dis)organization and therapeutic intervention: application to Alzheimer's disease," NeuroImage, vol. 152, pp. 60-77, 2017.

[22] J. M. Perez Ortiz and R. H. Swerdlow, "Mitochondrial dysfunction in Alzheimer's disease: role in pathogenesis and novel therapeutic opportunities," British Journal of Pharmacology, vol. 176, no. 18, pp. 3489-3507, 2019.

[23] J. K. Chambers, T. Tokuda, K. Uchida et al., "The domestic cat as a natural animal model of Alzheimer's disease," Acta Neuropathologica Communications, vol. 3, no. 1, 2015.

[24] E. Vallino Costassa, M. Fiorini, G. Zanusso et al., "Characterization of amyloid- $\beta$ deposits in bovine brains," Journal of Alzheimer's Disease, vol. 51, no. 3, pp. 875-887, 2016.

[25] D. Gunn-Moore, O. Kaidanovich-Beilin, M. C. Gallego Iradi, F. Gunn-Moore, and S. Lovestone, "Alzheimer's disease in humans and other animals: a consequence of postreproductive life span and longevity rather than aging," Alzheimer's \& Dementia, vol. 14, no. 2, pp. 195-204, 2018.

[26] S. E. Perez, C. C. Sherwood, M. R. Cranfield et al., "Early Alzheimer's disease-type pathology in the frontal cortex of wild mountain gorillas (_Gorilla beringei beringei_)," Neurobiology of Aging, vol. 39, pp. 195-201, 2016.

[27] D. Szabó, N. Gee, and Á. Miklósi, "Natural or pathologic? Discrepancies in the study of behavioral and cognitive signs in aging family dogs," Journal of Veterinary Behaviorclinical Applications and Research, vol. 11, pp. 86-98, 2016.

[28] E. Y. Yang, D. K. Lee, and J. H. Yang, "Environmental endocrine disruptors and neurological disorders," Journal of the Korean Neurological Association, vol. 36, no. 3, pp. 139-144, 2018.

[29] A. C. Gore, V. A. Chappell, S. E. Fenton et al., "EDC-2: The Endocrine Society's second scientific statement on endocrine-disrupting chemicals," Endocrine Reviews, vol. 36, no. 6, pp. E1-E150, 2015.

[30] R. T. Zoeller, T. R. Brown, L. L. Doan et al., "Endocrine-disrupting chemicals and public health protection: a statement 
of principles from The Endocrine Society," Endocrinology, vol. 153, no. 9, pp. 4097-4110, 2012.

[31] K. L. G. Russart and R. J. Nelson, "Light at night as an environmental endocrine disruptor," Physiology \& Behavior, vol. 190, pp. 82-89, 2018.

[32] L. N. Vandenberg, T. Colborn, T. B. Hayes et al., "Hormones and endocrine-disrupting chemicals: low-dose effects and nonmonotonic dose responses," Endocrine Reviews, vol. 33, no. 3, pp. 378-455, 2012.

[33] A. C. Gore, D. Crews, L. L. Doan, M. La Merrill, H. Patisaul, and A. Zota, "Introduction to endocrine disrupting chemicals (EDCs)," A guide for public interest organizations and policymakers, pp. 21-22, 2014.

[34] N. E. De Long and A. C. Holloway, "Early-life chemical exposures and risk of metabolic syndrome," Diabetes, Metabolic Syndrome and Obesity: Targets and Therapy, vol. Volume 10, pp. 101-109, 2017.

[35] B. Eskenazi, J. Chevrier, S. A. Rauch et al., "In utero and childhood polybrominated diphenyl ether (PBDE) exposures and neurodevelopment in the CHAMACOS study," Environmental Health Perspectives, vol. 121, no. 2, pp. 257-262, 2013.

[36] T. B. Hayes, A. Collins, M. Lee et al., "Hermaphroditic, demasculinized frogs after exposure to the herbicide atrazine at low ecologically relevant doses," Proceedings of the National Academy of Sciences, vol. 99, no. 8, pp. 5476-5480, 2002.

[37] E. O. Adegoke, M. S. Rahman, Y. J. Park, Y. J. Kim, and M. G. Pang, "Endocrine-disrupting chemicals and infectious diseases: from endocrine disruption to immunosuppression," International Journal of Molecular Sciences, vol. 22, no. 8, p. 3939, 2021.

[38] C. S. Rosenfeld, "Microbiome disturbances and autism spectrum disorders," Drug Metabolism and Disposition, vol. 43, no. 10, pp. 1557-1571, 2015.

[39] S. Lymperi and A. Giwercman, "Endocrine disruptors and testicular function," Metabolism, vol. 86, pp. 79-90, 2018.

[40] I. N. Pessah, P. J. Lein, R. F. Seegal, and S. K. Sagiv, "Neurotoxicity of polychlorinated biphenyls and related organohalogens," Acta Neuropathologica, vol. 138, no. 3, pp. 363-387, 2019.

[41] D. Luo, Y. Pu, H. Tian et al., “Association of in utero exposure to organochlorine pesticides with thyroid hormone levels in cord blood of newborns," Environmental Pollution, vol. 231, Part 1, pp. 78-86, 2017.

[42] B. Yilmaz, H. Terekeci, S. Sandal, and F. Kelestimur, "Endocrine disrupting chemicals: exposure, effects on human health, mechanism of action, models for testing and strategies for prevention," Reviews in Endocrine \& Metabolic Disorders, vol. 21, no. 1, pp. 127-147, 2020.

[43] L. De Toni, F. Tisato, R. Seraglia et al., "Phthalates and heavy metals as endocrine disruptors in food: a study on pre-packed coffee products," Toxicology Reports, vol. 4, pp. 234-239, 2017.

[44] H. B. Patisaul, "Endocrine disruption by dietary phyto-oestrogens: impact on dimorphic sexual systems and behaviours," The Proceedings of the Nutrition Society, vol. 76, no. 2, pp. 130-144, 2017.

[45] P. J. Kushner, D. A. Agard, G. L. Greene et al., "Estrogen receptor pathways to AP-1," The Journal of Steroid Biochemistry and Molecular Biology, vol. 74, no. 5, pp. 311-317, 2000.
[46] S. M. Belcher and A. Zsarnovszky, "Estrogenic actions in the brain: estrogen, phytoestrogens, and rapid intracellular signaling mechanisms," The Journal of Pharmacology and Experimental Therapeutics, vol. 299, no. 2, pp. 408-414, 2001.

[47] A. Nadal, E. Fuentes, C. Ripoll et al., "Extranuclear-initiated estrogenic actions of endocrine disrupting chemicals: is there toxicology beyond paracelsus?," The Journal of Steroid Biochemistry and Molecular Biology, vol. 176, pp. 16-22, 2018.

[48] E. K. Shanle and W. Xu, "Endocrine disrupting chemicals targeting estrogen receptor signaling: identification and mechanisms of action," Chemical Research in Toxicology, vol. 24, no. 1, pp. 6-19, 2011.

[49] N. Tagawa, S. Kubota, Y. Kobayashi, and I. Kato, "Genistein inhibits glucocorticoid amplification in adipose tissue by suppression of $11 \beta$-hydroxysteroid dehydrogenase type 1 ," Steroids, vol. 93, pp. 77-86, 2015.

[50] Y. L. Low, A. M. Dunning, M. Dowsett et al., "Implications of gene-environment interaction in studies of gene variants in breast cancer: an example of dietary isoflavones and the D356N polymorphism in the sex hormone-binding globulin gene," Cancer Research, vol. 66, no. 18, pp. 8980-8983, 2006.

[51] A. M. Mahmoud, W. Yang, and M. C. Bosland, "Soy isoflavones and prostate cancer: a review of molecular mechanisms," The Journal of Steroid Biochemistry and Molecular Biology, vol. 140, pp. 116-132, 2014.

[52] S. Lecomte, F. Demay, F. Ferrière, and F. Pakdel, "Phytochemicals Targeting Estrogen Receptors: Beneficial Rather Than Adverse Effects?," International Journal of Molecular Sciences, vol. 18, no. 7, p. 1381, 2017.

[53] D. S. Bar-El and R. Reifen, "Soy as an endocrine disruptor: cause for caution?," Journal of Pediatric Endocrinology \& Metabolism, vol. 23, no. 9, pp. 855-861, 2010.

[54] H. Wang and P. A. Murphy, "Isoflavone composition of American and Japanese soybeans in Iowa: effects of variety, crop year, and location," Journal of agricultural and food chemistry, vol. 42, no. 8, pp. 1674-1677, 1994.

[55] K. D. Setchell, "Phytoestrogens: the biochemistry, physiology, and implications for human health of soy isoflavones," The American Journal of Clinical Nutrition, vol. 68, no. 6, pp. 1333S-1346S, 1998.

[56] R. Meena, C. Supriya, K. Pratap Reddy, and R. P. Sreenivasula, "Altered spermatogenesis, steroidogenesis and suppressed fertility in adult male rats exposed to genistein, a non-steroidal phytoestrogen during embryonic development," Food and Chemical Toxicology, vol. 99, pp. 70-77, 2017.

[57] G. I. Russo, M. Di Mauro, F. Regis et al., “Association between dietary phytoestrogens intakes and prostate cancer risk in Sicily," The Aging Male, vol. 21, no. 1, pp. 48-54, 2018.

[58] S. Poschner, A. Maier-Salamon, M. Zehl et al., "The impacts of genistein and daidzein on estrogen conjugations in human breast cancer cells: a targeted metabolomics approach," Frontiers in Pharmacology, vol. 8, p. 699, 2017.

[59] P. F. Cheng, J. J. Chen, X. Y. Zhou et al., "Do soy isoflavones improve cognitive function in postmenopausal women? A meta-analysis," Menopause, vol. 22, no. 2, pp. 198-206, 2015.

[60] D. Kritz-Silverstein, D. Von Mühlen, E. Barrett-Connor, and M. A. Bressel, "Isoflavones and cognitive function in older women: the SOy and Postmenopausal Health In Aging (SOPHIA) Study," Menopause, vol. 10, no. 3, pp. 196-202, 2003. 
[61] C. E. Gleason, B. L. Fischer, N. M. Dowling et al., "Cognitive effects of soy isoflavones in patients with Alzheimer's disease," Journal of Alzheimer's Disease, vol. 47, no. 4, pp. 1009-1019, 2015.

[62] A. Sekikawa, M. Ihara, O. Lopez et al., "Effect of S-equol and soy isoflavones on heart and brain," Current Cardiology Reviews, vol. 15, no. 2, pp. 114-135, 2019.

[63] S. E. File, N. Jarrett, E. Fluck, R. Duffy, K. Casey, and H. Wiseman, "Eating soya improves human memory," Psychopharmacology, vol. 157, no. 4, pp. 430-436, 2001.

[64] T. Li, T. M. Badger, B. J. Bellando, S. T. Sorensen, X. Lou, and $\mathrm{X}$. Ou, "Brain cortical structure and executive function in children may be influenced by parental choices of infant diets," American Journal of Neuroradiology, vol. 41, no. 7, pp. 1302-1308, 2020.

[65] A. A. Thorp, N. Sinn, J. D. Buckley, A. M. Coates, and P. R. Howe, "Soya isoflavone supplementation enhances spatial working memory in men," The British Journal of Nutrition, vol. 102, no. 9, pp. 1348-1354, 2009.

[66] R. Z. Li, X. W. Ding, T. Geetha, L. Al-Nakkash, T. L. Broderick, and J. R. Babu, "Beneficial effect of genistein on diabetesinduced brain damage in the ob/ob mouse model," Drug Design, Development and Therapy, vol. 14, pp. 3325-3336, 2020.

[67] Y. J. Park, J. W. Ko, S. Jeon, and Y. H. Kwon, "Protective effect of genistein against neuronal degeneration in ApoE-/- mice fed a high-fat diet," Nutrients, vol. 8, no. 11, p. 692, 2016.

[68] R. Langasco, S. Fancello, G. Rassu et al., "Increasing protective activity of genistein by loading into transfersomes: a new potential adjuvant in the oxidative stress-related neurodegenerative diseases?," Phytomedicine, vol. 52, pp. 23-31, 2019.

[69] G. Rassu, E. P. Porcu, S. Fancello et al., "Intranasal delivery of genistein-loaded nanoparticles as a potential preventive system against neurodegenerative disorders," Pharmaceutics, vol. 11, no. 1, p. 8, 2018.

[70] J. W. Ko, Y.-S. Chung, C. S. Kwak, and Y. H. Kwon, "Doenjang, A Korean Traditional Fermented Soybean Paste, Ameliorates Neuroinflammation and Neurodegeneration in Mice Fed a High-Fat Diet," Nutrients, vol. 11, no. 8, p. 1702, 2019.

[71] K. V. Sandhu, Y. E. Demiray, Y. Yanagawa, and O. Stork, "Dietary phytoestrogens modulate aggression and activity in social behavior circuits of male mice," Hormones and Behavior, vol. 119, p. 104637, 2020.

[72] Y. Pan, M. Anthony, and T. B. Clarkson, "Evidence for upregulation of brain-derived neurotrophic factor mRNA by soy phytoestrogens in the frontal cortex of retired breeder female rats," Neuroscience Letters, vol. 261, no. 1-2, pp. 1720, 1999.

[73] A. Hussain, E. S. Tabrez, A. Muhammad, and J. R. Peela, “The mechanisms of dietary phytoestrogen as a potential treatment and prevention agent against Alzheimer's disease," Critical Reviews in Eukaryotic Gene Expression, vol. 28, no. 4, pp. 321-327, 2018.

[74] S. Khanna, R. Stewart, S. Gnyawali et al., "Phytoestrogen isoflavone intervention to engage the neuroprotective effect of glutamate oxaloacetate transaminase against stroke," The FASEB Journal, vol. 31, no. 10, pp. 4533-4544, 2017.

[75] J. W. Tan and M. K. Kim, "Neuroprotective effects of biochanin A against $\beta$-amyloid-induced neurotoxicity in PC12 cells via a mitochondrial-dependent apoptosis pathway," Molecules, vol. 21, no. 5, p. 548, 2016.

[76] A. Y. Choi, J. H. Choi, J. Y. Lee et al., "Apigenin protects HT22 murine hippocampal neuronal cells against endoplasmic reticulum stress-induced apoptosis," Neurochemistry International, vol. 57, no. 2, pp. 143-152, 2010.

[77] S. S. Kang, J. Y. Lee, Y. K. Choi, G. S. Kim, and B. H. Han, "Neuroprotective effects of flavones on hydrogen peroxideinduced apoptosis in SH-SY5Y neuroblostoma cells," Bioorganic \& Medicinal Chemistry Letters, vol. 14, no. 9, pp. 2261-2264, 2004.

[78] G. Losi, G. Puia, G. Garzon, M. C. de Vuono, and M. Baraldi, "Apigenin modulates GABAergic and glutamatergic transmission in cultured cortical neurons," European Journal of Pharmacology, vol. 502, no. 1-2, pp. 41-46, 2004.

[79] L. Subedi, E. Ji, D. Shin, J. Jin, J. H. Yeo, and S. Y. Kim, "Equol, a Dietary Daidzein Gut Metabolite Attenuates Microglial Activation and Potentiates Neuroprotection In Vitro," Nutrients, vol. 9, no. 3, p. 207, 2017.

[80] S. L. Johnson, H. Y. Park, D. A. Vattem, P. Grammas, H. Ma, and N. P. Seeram, "Equol, a blood-brain barrier permeable gut microbial metabolite of dietary isoflavone daidzein, exhibits neuroprotective effects against neurotoxins induced toxicity in human neuroblastoma SH-SY5Y cells and Caenorhabditis elegans," Plant Foods for Human Nutrition, vol. 75, no. 4, pp. 512-517, 2020.

[81] H. Khan, H. Ullah, M. Aschner, W. S. Cheang, and E. K. Akkol, "Neuroprotective effects of quercetin in Alzheimer's disease," Biomolecules, vol. 10, no. 1, p. 59, 2019.

[82] K. B. Magalingam, A. K. Radhakrishnan, and N. Haleagrahara, "Protective mechanisms of flavonoids in Parkinson's disease," Oxidative Medicine and Cellular Longevity, vol. 2015, Article ID 314560, 14 pages, 2015.

[83] J. H. Kim, S. Lee, E. J. Cho, and H. Y. Kim, "Neuroprotective effects of kaempferol, quercetin, and its glycosides by regulation of apoptosis," Journal of the Korea Academia-Industrial cooperation Society, vol. 20, no. 2, pp. 286-293, 2019.

[84] G. Abbruzzese, J. Morón-Oset, S. Díaz-Castroverde et al., "Neuroprotection by phytoestrogens in the model of deprivation and resupply of oxygen and glucose in vitro: the contribution of autophagy and related signaling mechanisms," Antioxidants, vol. 9, no. 6, p. 545, 2020.

[85] M. M. A. de Almeida, C. D. S. Souza, N. S. Dourado et al., "Phytoestrogen agathisflavone ameliorates neuroinflammation-induced by LPS and IL- $1 \beta$ and protects neurons in cocultures of glia/neurons," Biomolecules, vol. 10, no. 4, p. 562, 2020.

[86] H. S. Hafez, D. A. Ghareeb, S. R. Saleh et al., "Neuroprotective effect of ipriflavone against scopolamine-induced memory impairment in rats," Psychopharmacology, vol. 234, no. 20, pp. 3037-3053, 2017.

[87] R. Balez, N. Steiner, M. Engel et al., "Neuroprotective effects of apigenin against inflammation, neuronal excitability and apoptosis in an induced pluripotent stem cell model of Alzheimer's disease," Scientific Reports, vol. 6, no. 1, p. 31450, 2016.

[88] L. Zhao, J. L. Wang, R. Liu, X. X. Li, J. F. Li, and L. Zhang, "Neuroprotective, anti-amyloidogenic and neurotrophic effects of apigenin in an Alzheimer's disease mouse model," Molecules, vol. 18, no. 8, pp. 9949-9965, 2013.

[89] A. M. Sabogal-Guáqueta, J. I. Muñoz-Manco, J. R. RamírezPineda, M. Lamprea-Rodriguez, E. Osorio, and G. P. 
Cardona-Gómez, "The flavonoid quercetin ameliorates Alzheimer's disease pathology and protects cognitive and emotional function in aged triple transgenic Alzheimer's disease model mice," Neuropharmacology, vol. 93, pp. 134-145, 2015.

[90] N. Shveta, K. Rozy, and K. D. Devinder, "Neuroprotective role of quercetin against arsenic induced oxidative stress in rat brain," Journal of Environmental \& Analytical Toxicology, vol. 6, p. 359, 2016.

[91] K. H. Jeong, U. J. Jung, and S. R. Kim, "Naringin attenuates autophagic stress and neuroinflammation in kainic acidtreated hippocampus in vivo," Evidence-Based Complementary and Alternative Medicine, vol. 2015, Article ID 354326, 9 pages, 2015.

[92] S. F. Nabavi, N. Braidy, O. Gortzi et al., "Luteolin as an antiinflammatory and neuroprotective agent: a brief review," Brain Research Bulletin, vol. 119, no. Part A, pp. 1-11, 2015.

[93] T. Farkhondeh, H. S. Yazdi, and S. Samarghandian, "The protective effects of green tea catechins in the management of neurodegenerative diseases: a review," Current Drug Discovery Technologies, vol. 16, no. 1, pp. 57-65, 2019.

[94] S. J. Lee, E. Nam, H. J. Lee, M. G. Savelieff, and M. H. Lim, "Towards an understanding of amyloid- $\beta$ oligomers: characterization, toxicity mechanisms, and inhibitors," Chemical Society Reviews, vol. 46, no. 2, pp. 310-323, 2017.

[95] L. Ciccone, N. Tonali, S. Nencetti, and E. Orlandini, "Natural compounds as inhibitors of transthyretin amyloidosis and neuroprotective agents: analysis of structural data for future drug design," Journal of Enzyme Inhibition and Medicinal Chemistry, vol. 35, no. 1, pp. 1145-1162, 2020.

[96] Y. Wu, J. Geng, X. Lei, Q. Wu, T. Chen, and L. Zhong, "Glabridin downregulates lipopolysaccharide-induced oxidative stress and neuroinflammation in BV-2 microglial cells via suppression of nuclear factor- $\kappa \mathrm{B}$ signaling pathway," Pharmacognosy Magazine, vol. 16, no. 71, pp. 675-680, 2020.

[97] Y. Lee, S. Kim, Y. Oh, Y. M. Kim, Y. W. Chin, and J. Cho, "Inhibition of oxidative neurotoxicity and scopolamineinduced memory impairment by $\gamma$-mangostin: in vitro and in vivo evidence," Oxidative Medicine and Cellular Longevity, vol. 2019, Article ID 3640753, 14 pages, 2019.

[98] T. Ohgomori and S. Jinno, "Cuprizone-induced demyelination in the mouse hippocampus is alleviated by phytoestrogen genistein," Toxicology and Applied Pharmacology, vol. 363 , pp. 98-110, 2019.

[99] J. Wang, W. Y. Wu, H. Huang, W. Z. Li, H. Q. Chen, and Y. Y. Yin, "Biochanin a protects against lipopolysaccharideinduced damage of dopaminergic neurons both in vivo and in vitro via inhibition of microglial activation," Neurotoxicity Research, vol. 30, no. 3, pp. 486-498, 2016.

[100] R. Pluta, S. Januszewski, and S. J. Czuczwar, "Brain ischemia as a prelude to Alzheimer's disease," Frontiers in Aging Neuroscience, vol. 13, p. 636653, 2021.

[101] Y. Wang, Y. Shi, and H. Wei, "Calcium dysregulation in Alzheimer's disease: a target for new drug development," Journal of Alzheimer's Disease \& Parkinsonism, vol. 7, no. 5, p. 374, 2017.

[102] B. Stegmayr, K. Asplund, K. Kuulasmaa, A. M. Rajakangas, P. Thorvaldsen, and J. Tuomilehto, "Stroke incidence and mortality correlated to stroke risk factors in the WHO MONICA project. An ecological study of 18 populations," Stroke, vol. 28, no. 7, pp. 1367-1374, 1997.
[103] D. A. Schreihofer and L. Redmond, "Soy phytoestrogens are neuroprotective against stroke-like injury in vitro," Neuroscience, vol. 158, no. 2, pp. 602-609, 2009.

[104] V. Murugaiyah and M. P. Mattson, "Neurohormetic phytochemicals: an evolutionary-bioenergetic perspective," Neurochemistry International, vol. 89, pp. 271-280, 2015.

[105] J. Kim, D. Y. Fann, R. C. Seet, D. G. Jo, M. P. Mattson, and T. V. Arumugam, "Phytochemicals in ischemic stroke," Neuromolecular Medicine, vol. 18, no. 3, pp. 283-305, 2016.

[106] A. Murakami, "Modulation of protein quality control systems by food phytochemicals," Journal of Clinical Biochemistry and Nutrition, vol. 52, no. 3, pp. 215-227, 2013.

[107] F. R. Sharp, X. Zhan, and D. Z. Liu, "Heat shock proteins in the brain: role of Hsp70, Hsp 27, and HO-1 (Hsp32) and their therapeutic potential," Translational Stroke Research, vol. 4, no. 6, pp. 685-692, 2013.

[108] F. A. Wiegant, S. A. de Poot, V. E. Boers-Trilles, and A. M. Schreij, "Hormesis and cellular quality control: a possible explanation for the molecular mechanisms that underlie the benefits of mild stress," Dose Response, vol. 11, no. 3, pp. 413-430, 2012.

[109] A. Rahman, H. Jackson, H. Hristov et al., "Sex and gender driven modifiers of Alzheimer's: the role for estrogenic control across age, race, medical, and lifestyle risks," Frontiers in Aging Neuroscience, vol. 11, 2019.

[110] C. J. Pike, "Sex and the development of Alzheimer's disease," Journal of Neuroscience Research, vol. 95, no. 1-2, pp. 671680, 2017.

[111] M. S. Uddin, M. M. Rahman, M. Jakaria et al., "Estrogen signaling in Alzheimer's disease: molecular insights and therapeutic targets for Alzheimer's dementia," Molecular Neurobiology, vol. 57, no. 6, pp. 2654-2670, 2020.

[112] M. McCarthy and A. P. Raval, "The peri-menopause in a woman's life: a systemic inflammatory phase that enables later neurodegenerative disease," Journal of Neuroinflammation, vol. 17, no. 1, p. 317, 2020.

[113] O. Scheyer, A. Rahman, H. Hristov et al., "Female sex and Alzheimer's risk: the menopause connection," The Journal Of Prevention of Alzheimer's Disease, vol. 5, no. 4, pp. 225230, 2018.

[114] Y. J. Song, S. R. Li, X. W. Li et al., "The effect of estrogen replacement therapy on Alzheimer's disease and Parkinson's disease in postmenopausal women: a meta-analysis," Frontiers in Neuroscience, vol. 14, p. 157, 2020.

[115] H. Depypere, A. Vierin, S. Weyers, and A. Sieben, “Alzheimer's disease, apolipoprotein $\mathrm{E}$ and hormone replacement therapy," Maturitas, vol. 94, pp. 98-105, 2016.

[116] W. A. Rocca, J. H. Bower, D. M. Maraganore et al., "Increased risk of cognitive impairment or dementia in women who underwent oophorectomy before menopause," Neurology, vol. 69, no. 11, pp. 1074-1083, 2007.

[117] B. Imtiaz, M. Tuppurainen, T. Rikkonen et al., "Postmenopausal hormone therapy and Alzheimer disease: a prospective cohort study," Neurology, vol. 88, no. 11, pp. 1062 1068, 2017.

[118] C. Chávez-Pérez, A. Ceballos-Ramírez, and A. Suárez-Castro, "Efectos del uso del $17 \beta$-estradiol y la genisteína en la enfermedad de Alzheimer en mujeres con menopausia [Effects of the use of $17 \beta$-estradiol and genistein in Alzheimer's disease in women with menopause]," Revista Española de Geriatría y Gerontología, vol. 56, no. 4, pp. 236-240, 2021. 
[119] H. Guo, M. Liu, L. Zhang et al., "The critical period for neuroprotection by estrogen replacement therapy and the potential underlying mechanisms," Current Neuropharmacology, vol. 18, no. 6, pp. 485-500, 2020.

[120] C. Zhou, Q. Wu, Z. Wang, Q. Wang, Y. Liang, and S. Liu, "The effect of hormone replacement therapy on cognitive function in female patients with Alzheimer's disease: a meta-analysis," American Journal of Alzheimer's Disease and Other Dementias, vol. 35, p. 1533317520938585, 2020.

[121] H. Savolainen-Peltonen, P. Rahkola-Soisalo, F. Hoti et al., "Use of postmenopausal hormone therapy and risk of Alzheimer's disease in Finland: nationwide case-control study," BMJ, vol. 364, p. 1665, 2019.

[122] R. Luoto, S. Männistö, and E. Vartiainen, "Hormone replacement therapy and body size: how much does lifestyle explain?," American Journal of Obstetrics and Gynecology, vol. 178, 1 Part 1, pp. 66-73, 1998.

[123] C. Renoux, S. Dell'Aniello, and S. Suissa, "Hormone replacement therapy and the risk of venous thromboembolism: a population-based study," Journal of Thrombosis and Haemostasis, vol. 8, no. 5, pp. 979-986, 2010.

[124] J. C. Stevenson, "Hormone replacement therapy and cardiovascular disease revisited," Menopause International, vol. 15, no. 2, pp. 55-57, 2009.

[125] A. C. Moreira, A. M. Silva, M. S. Santos, and V. A. Sardão, "Phytoestrogens as alternative hormone replacement therapy in menopause: what is real, what is unknown," The Journal of Steroid Biochemistry and Molecular Biology, vol. 143, pp. 6171, 2014.

[126] V. Coxam, "Phyto-oestrogens and bone health," The Proceedings of the Nutrition Society, vol. 67, no. 2, pp. 184-195, 2008.

[127] E. L. Robb and J. A. Stuart, "Multiple phytoestrogens inhibit cell growth and confer cytoprotection by inducing manganese superoxide dismutase expression," Phytotherapy Research, vol. 28, no. 1, pp. 120-131, 2014.

[128] C. Carreau, G. Flouriot, C. Bennetau-Pelissero, and M. Potier, "Enterodiol and enterolactone, two major diet-derived polyphenol metabolites have different impact on ERalpha transcriptional activation in human breast cancer cells," The Journal of Steroid Biochemistry and Molecular Biology, vol. 110, no. 1-2, pp. 176-185, 2008.

[129] S. Md, S. Y. Gan, Y. H. Haw, C. L. Ho, S. Wong, and H. Choudhury, "In vitro neuroprotective effects of naringenin nanoemulsion against $\beta$-amyloid toxicity through the regulation of amyloidogenesis and tau phosphorylation," International Journal of Biological Macromolecules, vol. 118, no. Part A, pp. 1211-1219, 2018.

[130] M. Alemi, S. C. Silva, I. Santana, and I. Cardoso, "Transthyretin stability is critical in assisting beta amyloid clearancerelevance of transthyretin stabilization in Alzheimer's disease," CNS Neuroscience \& Therapeutics, vol. 23, no. 7, pp. 605-619, 2017.

[131] E. Y. Cotrina, A. Gimeno, J. Llop et al., "Calorimetric studies of binary and ternary molecular interactions between transthyretin, $\mathrm{A} \beta$ peptides, and small-molecule chaperones toward an alternative strategy for Alzheimer's disease drug discovery," 10.1021/acs.jmedchem.9b01970, vol. 63, no. 6, pp. 3205-3214, 2020.

[132] M. Messina, "Investigating the optimal soy protein and isoflavone intakes for women: a perspective," Womens Health, vol. 4, no. 4, pp. 337-356, 2008.
[133] G. Rizzo, "The antioxidant role of soy and soy foods in human health," Antioxidants, vol. 9, no. 7, p. 635, 2020.

[134] M. Yao, T. V. Nguyen, and C. J. Pike, "Estrogen regulates Bcl$\mathrm{w}$ and Bim expression: role in protection against betaamyloid peptide-induced neuronal death," Journal of Neuroscience, vol. 27, no. 6, pp. 1422-1433, 2007.

[135] P. Duarte-Guterman, S. E. Lieblich, C. Chow, and L. A. Galea, "Estradiol and GPER activation differentially affect cell proliferation but not GPER expression in the hippocampus of adult female rats," PLoS One, vol. 10, no. 6, article e0129880, 2015.

[136] T. W. Wu, J. M. Wang, S. Chen, and R. D. Brinton, "17Betaestradiol induced $\mathrm{Ca} 2+$ influx via L-type calcium channels activates the Src/ERK/cyclic-AMP response element binding protein signal pathway and BCL-2 expression in rat hippocampal neurons: a potential initiation mechanism for estrogen-induced neuroprotection," Neuroscience, vol. 135, no. 1, pp. 59-72, 2005.

[137] H. Yi, X. Bao, X. Tang, X. Fan, and H. Xu, "Estrogen modulation of calretinin and BDNF expression in midbrain dopaminergic neurons of ovariectomised mice," Journal of Chemical Neuroanatomy, vol. 77, pp. 60-67, 2016.

[138] Y. Zhao, J. Zhao, X. Zhang et al., "Botanical drug puerarin promotes neuronal survival and neurite outgrowth against $\mathrm{MPTP} / \mathrm{MPP}+$-induced toxicity via progesterone receptor signaling," Oxidative Medicine and Cellular Longevity, vol. 2020, Article ID 7635291, 11 pages, 2020.

[139] I. M. C. M. Rietjens, J. Louisse, and K. Beekmann, "The potential health effects of dietary phytoestrogens," British Journal of Pharmacology, vol. 174, no. 11, pp. 1263-1280, 2017.

[140] S. Sahab-Negah, V. Hajali, H. R. Moradi, and A. Gorji, “The impact of estradiol on neurogenesis and cognitive functions in Alzheimer's disease," Cellular and Molecular Neurobiology, vol. 40, no. 3, pp. 283-299, 2020.

[141] K. Keyvani, Y. Münster, N. K. Kurapati et al., "Higher levels of kallikrein-8 in female brain may increase the risk for Alzheimer's disease," Brain Pathology, vol. 28, no. 6, pp. 947964, 2018.

[142] M. Alvarez-de-la-Rosa, I. Silva, J. Nilsen et al., "Estradiol prevents neural tau hyperphosphorylation characteristic of Alzheimer's disease," Annals of the New York Academy of Sciences, vol. 1052, pp. 210-224, 2005.

[143] J. C. Means, A. A. Lopez, and P. Koulen, "Estrogen protects optic nerve head astrocytes against oxidative stress by preventing caspase-3 activation, tau dephosphorylation at Ser422 and the formation of tau protein aggregates," Cellular and Molecular Neurobiology, vol. 41, no. 3, pp. 449-458, 2021.

[144] Z. Zhenxia, L. Min, Y. Peikui et al., "Inhibition of tau aggregation and associated cytotoxicity on neuron-like cells by calycosin," International Journal of Biological Macromolecules, vol. 171, pp. 74-81, 2021.

[145] Y. J. Park, Y. M. Jang, and Y. H. Kwon, "Isoflavones prevent endoplasmic reticulum stress-mediated neuronal degeneration by inhibiting tau hyperphosphorylation in SH-SY5Y cells," Journal of Medicinal Food, vol. 12, no. 3, pp. 528535, 2009.

[146] F. D. S. Petry, B. P. Coelho, M. M. Gaelzer et al., "Genistein protects against amyloid-beta-induced toxicity in SH-SY5Y cells by regulation of Akt and tau phosphorylation," Phytotherapy Research, vol. 34, no. 4, pp. 796-807, 2020. 
[147] S. Ye, T. T. Wang, B. Cai et al., "Genistein protects hippocampal neurons against injury by regulating calcium/calmodulin dependent protein kinase IV protein levels in Alzheimer's disease model rats," Neural Regeneration Research, vol. 12, no. 9, pp. 1479-1484, 2017.

[148] E. Y. L. Liu, M. L. Xu, Y. Jin, Q. Wu, T. T. X. Dong, and K. W. K. Tsim, "Genistein, a phytoestrogen in soybean, induces the expression of acetylcholinesterase via G protein-coupled receptor 30 in PC12 cells," Frontiers in Molecular Neuroscience, vol. 11, 2018.

[149] A. Cattaneo and P. Calissano, "Nerve growth factor and Alzheimer's disease: new facts for an old hypothesis," Molecular Neurobiology, vol. 46, no. 3, pp. 588-604, 2012.

[150] S. Mitra, H. Behbahani, and M. Eriksdotter, "Innovative therapy for Alzheimer's disease-with focus on biodelivery of NGF," Frontiers in Neuroscience, vol. 13, 2019.

[151] A. C. Cuello, R. Pentz, and H. Hall, "The brain NGF metabolic pathway in health and in Alzheimer's pathology," Frontiers in Neuroscience, vol. 13, 2019.

[152] S. R. Wilkenfeld, C. Lin, and D. E. Frigo, "Communication between genomic and non-genomic signaling events coordinate steroid hormone actions," Steroids, vol. 133, pp. 2-7, 2018.

[153] P. Morley, J. F. Whitfield, B. C. Vanderhyden, B. K. Tsang, and J. L. Schwartz, "A new, nongenomic estrogen action: the rapid release of intracellular calcium," Endocrinology, vol. 131, no. 3, pp. 1305-1312, 1992.

[154] A. Demuro, I. Parker, and G. E. Stutzmann, "Calcium signaling and amyloid toxicity in Alzheimer disease," Journal of Biological Chemistry, vol. 285, no. 17, pp. 12463-12468, 2010.

[155] E. Hogervorst, S. Kassam, A. Kridawati et al., "Nutrition research in cognitive impairment/dementia, with a focus on soya and folate," The Proceedings of the Nutrition Society, vol. 76, no. 4, pp. 437-442, 2017.

[156] M. S. Uddin and M. T. Kabir, "Emerging signal regulating potential of genistein against Alzheimer's disease: a promising molecule of interest," Frontiers in Cell and Developmental Biology, vol. 7, 2019.

[157] D. Mohammad, P. Chan, J. Bradley, K. Lanctôt, and N. Herrmann, "Acetylcholinesterase inhibitors for treating dementia symptoms - a safety evaluation," Expert Opinion on Drug Safety, vol. 16, no. 9, pp. 1009-1019, 2017. 